\title{
Bioaccumulation of selenium-by fruit origin lactic acid bacteria in tropical fermented fruit juices
}

\author{
Laura Crespo $^{\text {a }}$, Raimondo Gaglio ${ }^{\mathrm{b}}$, Fernando G. Martínez ${ }^{\mathrm{a}}$, Gustavo Moreno Martin ${ }^{\mathrm{d}}$, \\ Elena Franciosi ${ }^{\mathrm{c}}$, Yolanda Madrid-Albarrán ${ }^{\mathrm{d}}$, Luca Settanni ${ }^{\mathrm{b}}$, Fernanda Mozzi ${ }^{\mathrm{a}}$, \\ Micaela Pescuma ${ }^{\text {a, }}$ \\ ${ }^{a}$ CERELA-CONICET, Chacabuco 145, San Miguel de Tucumán, 4000, Argentina \\ ${ }^{\mathrm{b}}$ Department of Agricultural, Food and Forest Science, Università degli Studi di Palermo, Viale delle Scienze 4, 90128, Palermo, Italy \\ ${ }^{\mathrm{c}}$ Research and Innovation Centre, Fondazione Edmund Mach (FEM), Via E. Mach 1, San Michele all'Adige, Italy \\ d Departamento de Química Analítica, Facultad de Ciencias Químicas, Universidad Complutense de Madrid, Madrid, Spain
}

\section{A R T I C L E I N F O}

\section{Keywords:}

Mango

Passion fruit

Fructobacillus tropaeoli

Levilactobacillus brevis

Essential micronutrients

\begin{abstract}
A B S T R A C T
Adequate fruit consumption helps to prevent several chronic age-related diseases. Selenium (Se) is an elemental micronutrient with antioxidant capacity. In general, fruits and Se ingest by humans are below the recommended daily intake value. Fresh fruits are highly susceptible to deterioration during storage. Fermentation can improve the storage period, sensory profile, and bioactive compound content of foods; moreover, some lactic acid bacteria can accumulate organic Se intracellularly. In this work, microbial growth and Se accumulation by Levilactobacillus brevis CRL2051 and Fructobacillus tropaeoli CRL2034 in tropical fruit juices were evaluated. The strains could grow 1-2 log cfu/mL, alone or combined, in mango, passion fruit, and mango/passion fruit juices, although they could not completely eliminate native microorganisms in unpasteurised juices. In pasteurised trials, both strains consumed fruit carbohydrates producing lactic acid, in addition to acetic acid, and mannitol by F. tropaeoli. Both strains accumulated Se intracellularly in the fruit juices, especially $(123.0 \mu \mathrm{g} / \mathrm{L})$ in the passion fruit juice fermented by the mixed culture. Finally, the Fructobacillus strain increased 3.42 times the phenolic compound concentration in the mango/passion fruit juice with added Se after $24 \mathrm{~h}$. The assayed LAB strains could be used for preparing functional fermented fruit beverages bio-enriched in Se.
\end{abstract}

\section{Introduction}

Fruits and vegetables are poorly consumed comparing to the WHO recommended daily intake (https://www.who.int). However, fruits and vegetables are unique sources of fibres, vitamins, and other bioactive compounds necessary to prevent cardiovascular diseases, aging, and different types of cancer (Bates, Morris, \& Crandall, 2001).

Mango (Mangifera indica L.) is grown worldwide constituting the fifth most cultivated crop (42.1 million Mt/year) (Vithana, Singh, \& Johnson, 2019) and is the second most cultivated tropical fruit after banana. Argentina produces $6640 \mathrm{t}$ and its production has increased in the last 5 years. On the other hand, passion fruit (Passiflora dulcis) is grown in most tropical and subtropical areas of the world. While Brazil stands for $90 \%$ of the world production (478,000 t/year) (Joy, 2014), in Argentina yellow passion fruit has been recently included as a cultivable fruit in the northwest part of the country. Mango and passion fruit contain carotenoid levels significantly higher than other tropical fruits such as litchi, papaya, pineapple, and banana (Septembre-Malaterre, Stanislas, Douraguia, \& Gonthier, 2016).

Fruits are usually consumed fresh or as juices, salads, and sauces. The main disadvantage of fruits is their fast spoilage (Di Cagno, Coda, De Angelis, \& Gobbetti, 2013). Different approaches have been proposed for increasing fruit shelf life as pasteurization, new packaging, etc. (Garcia, Guérin, Souidi, \& Remize, 2020). Within these strategies, lactic acid fermentation is a low cost and simple technology which can improve shelf life, sensory profile and release bioactive compounds without negatively affect the nutritional properties of fruits (Swain, Anandharaj, Ray, \& Parveen Rani, 2014). Fruits are acidic environments and contain non digestive nutrients (fibre, inulin, fructooligosaccharides) and phenolic compounds which can have growth inhibitory

\footnotetext{
* Corresponding author.

E-mail addresses: fmozzi@cerela.org.ar (F. Mozzi), mpescuma@ciefap.org.ar (M. Pescuma).
} 
effects (Szutowska, 2020). The ability of lactic acid bacteria (LAB) to grow in fruits depends on specific metabolic traits given by the presence of enzymes (levansucrase, tannase, and phytase, among others), which result from the adaptation of LAB strains to the fruit niche (Endo, 2012; Siezen \& Bachmann, 2008). In this respect, it has been shown that the use of autochthonous LAB as starter cultures provide better characteristics (color, firmness, antioxidant activity, etc.) to the final product than allochthonous strains (Ruiz Rodríguez et al., 2021).

Selenium (Se) is an essential micronutrient which is known to be in low concentration in the soil of many countries. Although Se has been added in the soil for fortifying crops, its absorption and biotransformation into organic and more available forms depends on the plant species. Some LAB can biotransform inorganic sodium selenite into organic Se nanoparticles and seleno-amino acids (SeMet and SeCys) (Martínez, Martin-Moreno, Pescuma, Madrid-Albarrán, \& Mozzi, 2020). At the moment, consumers demand for functional foods with low caloric content, high nutritional value, and free of milk derivatives are continuously increasing (Granato, Branco, Cruz, Faria, \& Nazzaro, 2010). Se bio-enriched fermented fruit juices could be a promising alternative for formulating low caloric, free of cholesterol functional foods also suitable for vegans and lactose intolerant individuals. In a previous work, Ruiz Rodriguez et al. (2019) isolated 95 LAB strains from 8 different tropical fruits from Northwestern Argentina. Levilactobacillus brevis CRL 2051 and Fructobacillus tropaeoli CRL 2034 were selected among the others, for their growth rate, acidifying capacity, and their inability to produce biogenic amines in a fruit simulation medium (Ruiz Rodriguez et al., 2019). Furthermore, these strains showed high Se accumulation and SeCys production in MRS broth supplemented with sodium selenite (Martínez et al., 2020), and were able to survive the gastrointestinal tract environment and remain viable in a Se enriched fruit-milk based beverage during storage $\left(4{ }^{\circ} \mathrm{C}, 28\right.$ days) (Martínez, Cuencas Barrientos, Mozzi, \& Pescuma, 2019). In this work, we aimed to evaluate the ability of $L$. brevis CRL 2051 and F. tropaeoli CRL 2034 to grow and bio-accumulate Se in mango, passion fruit, and mango/passion fermented fruit juices.

\section{Materials and methods}

\subsection{Fruit juice preparations and microbial starter strains}

Passion fruit and mango fruits were collected in the Argentinean provinces of Jujuy and Tucumán, respectively. Before peeling and squeezing, mango and passion fruit underwent a washing procedure including a step of $2 \mathrm{~min}$ in chlorinate water solution $(0.2 \%, \mathrm{v} / \mathrm{v})$ followed by a rinse in cold $\left(4^{\circ} \mathrm{C}\right)$ water to remove chlorine (Alfonzo et al., 2018). Mango and passion fruit juices were, separately, first filtered and then diluted in sterile tap water to a final juice/water ratio of 30:70. The $\mathrm{pH}$ of the diluted juices was increased, if necessary, with a sterile sodium bicarbonate solution $(20 \%, \mathrm{w} / \mathrm{v})$ to obtain a final $\mathrm{pH}$ of 4.2 . Each juice was separated into two aliquots. The pasteurised samples were subjected to pasteurization in a water bath at $80{ }^{\circ} \mathrm{C}$ for $5 \mathrm{~min}$. The temperature inside the bottles was monitored by submerging a thermometer in a similar bottle containing water; when the temperature of $80{ }^{\circ} \mathrm{C}$ was reached, the bottles were maintained during $5 \mathrm{~min}$, and submerged in an ice bath immediately after. The raw fruit juice samples remained thermically untreated.

Levilactobacillus brevis CRL 2051 and Fructobacillus tropaeoli CRL 2034 (Culture Collection of CERELA-CONICET, Tucumán, Argentina) were previously isolated from tropical fruits (Ruiz et al. 2019) and selected for their ability to produce seleno-proteins and seleno-nanoparticles as mentioned above (Martínez et al., 2019; Martínez et al., 2020). Both strains were propagated microaerobically in MRS broth (Britania, Buenos Aires, Argentina) with the addition of $2 \%(\mathrm{w} / \mathrm{v})$ of fructose (Sigma-Aldrich Chemical Co, MO) (MRSf) at $30^{\circ} \mathrm{C}$ for $48 \mathrm{~h}$ before inoculation.

\subsection{Juice fermentation process and microbiological analyses}

LAB cells were centrifuged at $5000 \mathrm{~g} \times 5 \mathrm{~min}$ and washed twice in physiological solution $(\mathrm{NaCl}, 0.85 \%, \mathrm{w} / \mathrm{v})$ and inoculated individually in each fruit juice $(1 \mathrm{~L})$, separately or combined in a 1:1 mango/passion fruit juice ratio, at the final density of $10^{7} \mathrm{cfu} / \mathrm{mL}$; when corresponding, both strains were co-cultured at 1:1 (v/v) ratio. Pasteurised and raw juice trials were accompanied by trials containing $0.15 \mathrm{mg} / \mathrm{L}$ of Se, as sodium selenite (Sigma-Aldrich). The corresponding sample codes are shown in Table 1 . All juices were incubated at $30{ }^{\circ} \mathrm{C}$ for $24 \mathrm{~h}$. Assays were performed in duplicate and repeated after two weeks to obtain two independent experimentations with two technical repeats for each production day, providing four data per parameter.

Fermented juices, were investigated for the following microbial groups: total mesophilic count (TMC) by spread plating on plate count agar (PCA) (Britania), incubated aerobically at $30{ }^{\circ} \mathrm{C}$ for $72 \mathrm{~h}$; Enterobacteriaceae by pour plating on double-layered violet red bile glucose agar (VRBGA) (Britania), incubated aerobically at $37^{\circ} \mathrm{C}$ for $24 \mathrm{~h}$; LAB by pour plating on MRS agar (Britania), incubated anaerobically at $30^{\circ} \mathrm{C}$ for $48 \mathrm{~h}$. All plates used for bacteria detection and quantification were supplemented with cycloheximide (0.1 g/L) (Sigma-Aldrich). Yeasts were detected by spread plating on yeast peptone dextrose (YPD) agar added with chloramphenicol $(0.1 \mathrm{~g} / \mathrm{L})$ (Sigma-Aldrich) and incubated at $28{ }^{\circ} \mathrm{C}$ for $48 \mathrm{~h}$. The acidification process of fermented and nonfermented fruit juices was monitored by $\mathrm{pH}$.

\subsection{Persistence of starter strains by RAPD-PCR}

The dominance of the strains added as starter cultures over indigenous fruit juice microorganisms and their persistence over time was analyzed at the end of fermentation of non-pasteurised juices by randomly amplified polymorphic DNA (RAPD)-PCR as reported by Alfonzo et al. (2016). The colonies developed from the highest dilutions of the cell suspensions plated on MRS were randomly collected (at least three colonies with identical appearance in terms of colour, shape, surface, edge and elevation) and, after purification by consecutive sub-culturing on the same media, characterized for their Gram type by $\mathrm{KOH}(3 \%, \mathrm{w} / \mathrm{v})$ treatment and catalase activity by $\mathrm{H}_{2} \mathrm{O}_{2}(5 \%, \mathrm{v} / \mathrm{v})$ exposure (Cruciata et al., 2018). Only Gram-positive and catalase-negative cultures were subjected to RAPD-PCR to compare their polymorphic patterns to those of the axenic cultures of $L$. brevis CRL 2051 and F. tropaeoli CRL 2034.

\subsection{Illumina library and sequencing of pasteurised fermented fruit juices}

To deeply investigate the presence of the added LAB strains among the total bacterial communities of the inoculated and non-inoculated unpasteurised tropical juices, they were subjected to high throughput sequence analysis by MiSeq Illumina. DNA was extracted from the juice

Table 1

Codes for fruit (mango, passion fruit, and mango passion fruit) juice trials in raw and pasteurised samples.

\begin{tabular}{|c|c|}
\hline Codes & Trials \\
\hline Control & Non inoculated fruit juice \\
\hline CRL2051 & Fruit juice inoculated with $L$. brevis CRL 2051 \\
\hline CRL2034 & Fruit juice inoculated with F. tropaeoli CRL 2034 \\
\hline $\begin{array}{r}\text { CRL2051 }+ \\
\text { CRL2034 }\end{array}$ & $\begin{array}{l}\text { Fruit juice inoculated with } L \text {. brevis CRL } 2051 \text { and F. tropaeoli } \\
\text { CRL } 2034\end{array}$ \\
\hline Control Se & Non inoculated fruit juice containing $\mathrm{Na}_{2} \mathrm{SeO}_{3}$ \\
\hline CRL2051 Se & $\begin{array}{l}\text { Fruit juice containing } \mathrm{Na}_{2} \mathrm{SeO}_{3} \text { inoculated with } L \text {. brevis } \mathrm{CRL} \\
2051\end{array}$ \\
\hline CRL2034 Se & $\begin{array}{l}\text { Fruit juice containing } \mathrm{Na}_{2} \mathrm{SeO}_{3} \text { inoculated with } F \text {. tropaeoli CRL } \\
2034\end{array}$ \\
\hline $\begin{array}{r}\text { CRL2051 }+ \\
\text { CRL2034 }\end{array}$ & $\begin{array}{l}\text { Fruit juice containing } \mathrm{Na}_{2} \mathrm{SeO}_{3} \text { inoculated with } L \text {. brevis CRL } \\
2051 \text { and F. tropaeoli CRL } 2034\end{array}$ \\
\hline
\end{tabular}


samples using QIAamp ${ }^{\circledR}$ DNA Investigator Kit (Qiagen, Hilden, Germany) and diluted to $5 \mathrm{ng} / \mu \mathrm{L}$ in $10 \mathrm{mMTris}$ (Sigma-Aldrich, Milan, Italy) $\mathrm{pH}$ 8.5. The 16S rDNA amplicon library was constructed using the primer set $341 \mathrm{~F}$ and $806 \mathrm{R}$ to amplify the V3-V4 region of the $16 \mathrm{~S}$ rDNA gene (Baker, Smith, \& Cowan, 2003). Unique barcodes were attached before the forward primers to facilitate the pooling and subsequent differentiation of samples. To prevent preferential sequencing of smallest amplicons, the amplicons were cleaned using the Agencourt AMPure kit (Beckman coulter) according to manufacturer's instructions. Before sequencing, amplicons were quantified using the Quant-iT PicoGreen dsDNA kit (Invitrogen) following the manufacturer's instructions. To ensure the absence of primer dimers and to assay the purity, the generated amplicon libraries quality was evaluated by a Bioanalyzer 2100 (Agilent, Palo Alto, CA, USA) using the High Sensitivity DNA Kit (Agilent). Following quantitation, the cleaned amplicons were pooled in equimolar ratios on an Illumina MiSeq platform (Illumina Inc., San Diego, CA, USA), according to the standard protocols. Pair-end sequencing was carried out at Genomic Platform - Fondazione Edmund Mach (San Michele a/Adige, Trento, Italy).

\subsection{S rDNA metabarcoding data analysis}

Raw paired-end FASTQ files were demultiplexed using idemp (htt ps://github.com/yhwu/idemp/blob/master/idemp.cpp) and imported into Quantitative Insights Into Microbial Ecology (Qiime2, version 2020.11). Quality control, trimming, denoising, merging, chimeric sequence filtering, and feature table construction were performed using the q2-dada2 plugin (Callahan et al., 2016). Taxonomic classification, clustering, and dereplicating with $99 \%$ similarity were done using the Feature-classifier plugin (Bokulich et al., 2018) against a pre-trained Naive Bayes classifier based on the Greengenes Operational Taxonomic Units (OTUs) database (http://greengenes.secondgenome.com/), which had been previously trimmed to the V4 region of $16 \mathrm{~S}$ rDNA, bound by the $341 \mathrm{~F} / 805 \mathrm{R}$ primer pair.

The data generated by Illumina sequencing were deposited in the NCBI Sequence Read Archive (SRA) and are available under Ac. PR JNA693786 from biosample SAMN17435143 to SAMN17435150.

\subsection{Carbohydrate metabolism}

Carbohydrate (glucose, fructose, and sucrose) utilization and organic acids (lactic and acetic acid), ethanol, and mannitol production by the studied strains were determined in fermented fruit juice samples at 0 and $24 \mathrm{~h}$ by High Performance Liquid Chromatography (HPLC). HPLC was performed using a Knauer Smartline System HPLC (Berlin, Germany) with a Knauer Smartline 2600 UV detector. To determine organic acids and ethanol, a Biorad Aminex ${ }^{\circledR} \mathrm{HPX}-87 \mathrm{H}$ column $(300 \times 7.8 \mathrm{~mm}$, Hercules, CA) was used. The elution conditions were as follows: $5 \mathrm{mM} / \mathrm{L}$ $\mathrm{H}_{2} \mathrm{SO}_{4}$ was used as eluent at a flow rate of $0.6 \mathrm{~mL} / \mathrm{min}$ and an internal temperature of $41{ }^{\circ} \mathrm{C}$. For carbohydrates and mannitol determination, a Sugar Pak I-WATERS (Milford, MA, USA) column $(10 \mu, 6.5 \mathrm{~mm} \times 300$ $\mathrm{mm}$ ) was used with deionized water as mobile phase with a flow rate of $0.5 \mathrm{~mL} / \mathrm{min}$ and an internal temperature of $85{ }^{\circ} \mathrm{C}$. Samples were previously deproteinized according to the Carrez method, desalted using amberlite resin IR 45 and IR 120 (BDH, laboratory supplies, Pool, UK), passed through $0.2 \mu \mathrm{m}$ filters (Sartorius AG, Gotinga, Germany) (Ortiz, Fornaguera, Raya, \& Mozzi, 2012) and kept at $-20{ }^{\circ} \mathrm{C}$ until HPLC analysis.

\subsection{Determination of selenium concentration}

Control and Se-enriched fruit juices $(25 \mathrm{~mL})$ were centrifuged $\left(10,000 \mathrm{~g}, 20 \mathrm{~min} 4{ }^{\circ} \mathrm{C}\right)$ and the microbial pellets were washed twice with deionized water. The obtained pellets $(0.1 \mathrm{~g})$ were submitted to acid digestion in a $1000 \mathrm{~W}$ microwave oven (MSP microwave oven, CEM, Matthews, NC, USA) using closed vessels containing $1 \mathrm{~mL}$ of concentrated $\mathrm{HNO}_{3}$ and $0.5 \mathrm{~mL}$ of $30 \%(\mathrm{v} / \mathrm{v}) \mathrm{H}_{2} \mathrm{O}_{2}$ (Pescuma, Gómez Gómez, Perez Corona, Madrid, \& Mozzi, 2017). The resulting solutions were cooled down, diluted to a $25 \mathrm{~mL}$ final volume with MilliQ water and analyzed for the Se concentration with an Agilent 7700-collision/reaction cell ICP-MS (Agilent Technologies, Santa Clara, CA, USA). Hydrogen gas was employed as collision gas for Se determination. The analyses were carried out in the same conditions described by Pescuma et al. (2017) and Martínez et al. (2020).

\subsection{Total phenolic compound content of fermented juices}

Fermented and non-fermented (control) juices were centrifuged $(10,000 \mathrm{~g}, 10 \mathrm{~min})$ and soluble phenolic compounds were analyzed in the supernatants using the Folin-Ciocalteu method (Singleton Orthofer \& Lamuela-Raventos, 1999) in a 96 well plate. Briefly, $10 \mu \mathrm{l}$ of each sample were mixed with $50 \mu$ of the Folin-Ciocalteu reagent and were incubated $10 \mathrm{~min}$ at room temperature in the dark. Samples were diluted with $150 \mu \mathrm{l}$ of $\mathrm{Na}_{2} \mathrm{CO}_{3} 2 \%(\mathrm{w} / \mathrm{v}$ ) and $750 \mu \mathrm{l}$ deionized water, mixed, an incubated for $2 \mathrm{~h}$. The absorbance was measured at $760 \mathrm{~nm}$ with a Versamax Microplate reader (Molecular Devices, CA, USA) and results were compared with a calibration curve using gallic acid as standard $(0.025-2000 \mathrm{mg} / \mathrm{mL})$; and were informed as $\mathrm{mg} / \mathrm{ml}$ of gallic acid (GAE).

\subsection{Statistical analysis}

All assays were carried out in triplicate and data are expressed as mean values with standard deviations. One-way analysis of variance (ANOVA) and Tukey's post comparison test using MINITAB 16 Statistical Software (Minitab, State College, PA, USA) was applied for statistical analysis.

\section{Results}

\subsection{Fermentation of tropical fruit juices}

F. tropaeoli CRL 2034 and L. brevis CRL 2050 grew (1-2 log cfu/ml) alone or combined in mixed cultures in the three assayed juice preparations: mango, passion fruit, and the mixture mango/passion fruit (1:1, $\mathrm{v} / \mathrm{v}$ ) either using pasteurised or raw samples (Figs. 1-3). All raw juices showed the presence of indigenous microorganisms in samples at the beginning and/or the end of the fermentation. However, non-inoculated mango and mango/passion fruit juices showed higher microbial load than the passion fruit ones as observed in the PCA and MRS plates (Figs. 1-3). Bacterial cell count values of non-inoculated mango juice samples without Se were 8.5-8.8 log cfu/ml either in PCA or MRS plates after $24 \mathrm{~h}$ incubation (Fig. 1). In the non-inoculated mango/passion fruit juices, lower cell count values $(1.8-2.5 \log \mathrm{cfu} / \mathrm{ml})$ at time 0 in MRS and PCA plates were observed, reaching values between 8.3 and $8.7 \log \mathrm{cfu} /$ $\mathrm{ml}$ in MRS and 6.4-6.5 log cfu/ml in PCA after incubation at $30{ }^{\circ} \mathrm{C}$ for $24 \mathrm{~h}$ (Fig. 3). On the other hand, the lowest cell count values corresponded to the non-inoculated passion fruit juices without Se either in MRS or PCA plates after $24 \mathrm{~h}$ incubation (1.0-2.6 log cfu/ml, and 0.0-1.2 log cfu/ml, respectively) (Fig. 2). In mango and mango/passion fruit juices the final cell counts $(24 \mathrm{~h})$ in MRS were similar for the inoculated and control samples. On the opposite, in passion fruit juices the cell counts were lower $(0.7$ and $1.8 \mathrm{log} \mathrm{cfu} / \mathrm{ml})$ in the control samples than in the inoculated juices (8.5-8.8 $\log \mathrm{cfu} / \mathrm{ml}$ ) at $24 \mathrm{~h}$ (Fig. 2). Furthermore, molds and yeasts were not detected in the passion fruit juice samples, while both groups were observed at time 0 (0.0-2.2 log $\mathrm{cfu} / \mathrm{ml}$, and 0.0-1.1 log cfu/ml, respectively) and $24 \mathrm{~h}$ (1.0-0.0 log cfu/ $\mathrm{ml}$, and 1.0-1.7 log cfu/ml, respectively) in mango, and mango/passion fruit juices (2.7-2.5 log $\mathrm{cfu} / \mathrm{ml}$ and 5.6-5.7 $\log \mathrm{cfu} / \mathrm{ml}$, respectively) (Figs. 1 and 3). However, when mango juices were inoculated with F. tropaeoli CRL2034 or the mixed starter culture no molds or yeasts were detected after $24 \mathrm{~h}$, while in mango/passion fruit juices an inhibition of molds and yeast growth was observed only for the samples inoculated 


\section{Raw-MRS}

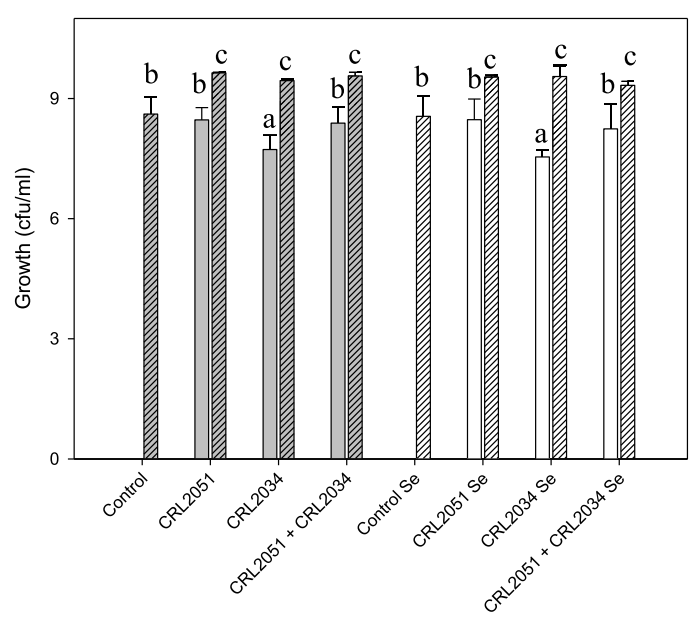

Raw-YPD-Yeast

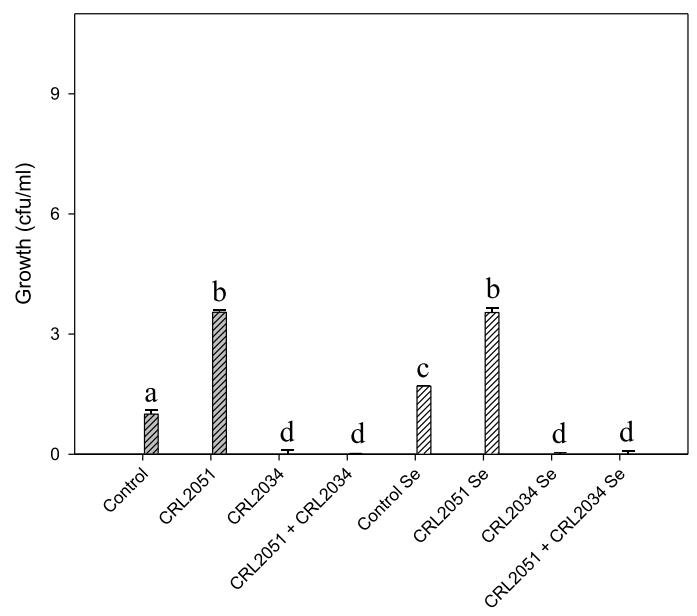

Pasteurised-MRS

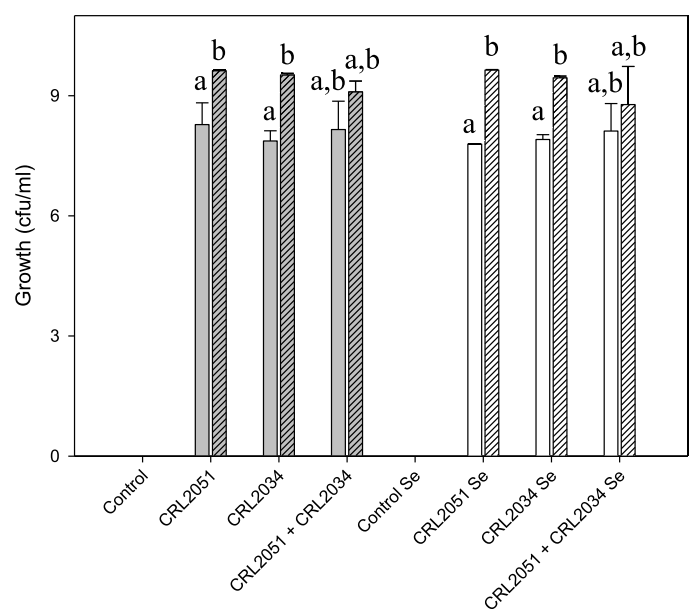

Raw-PCA

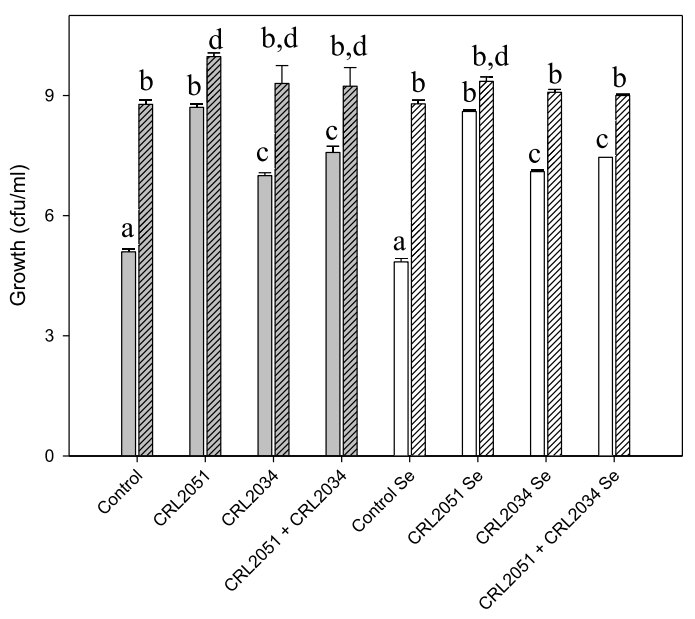

Raw-YPD-Molds

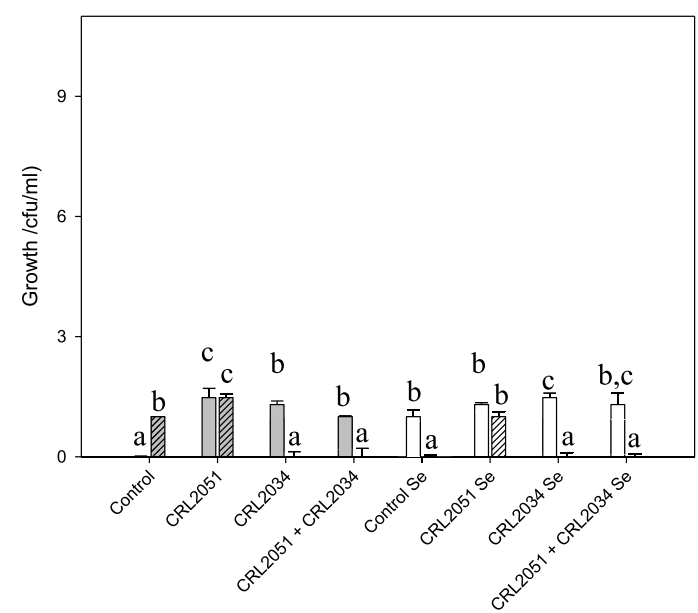

Pasteurised-PCA

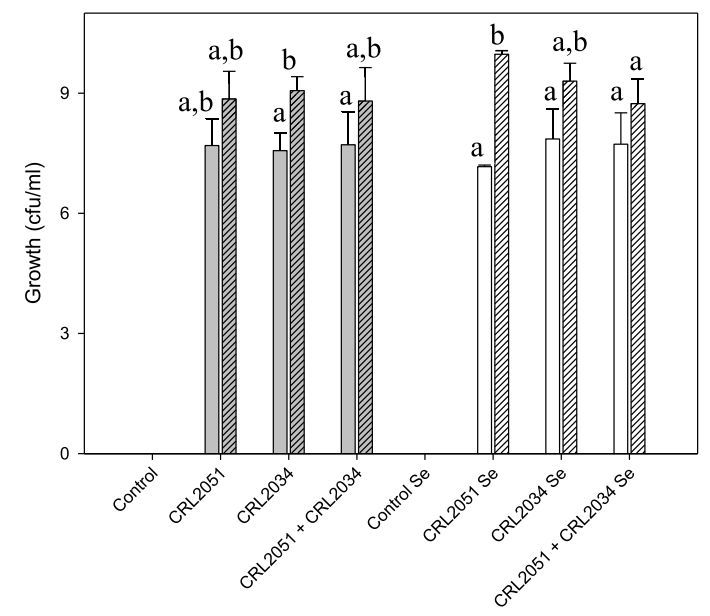

Fig. 1. Growth (cfu/ml) of L. brevis CRL 2051 (CRL2051), F. tropaeoli CRL 2034 (CRL2034) and the mixed culture of both strains (CRL2051 + CRL2034) in mango

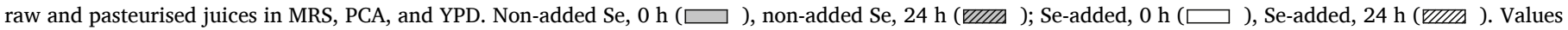
with different superscripts represent significant statistically data $(\mathrm{P}<0.05)$. 


\section{Raw-MRS}

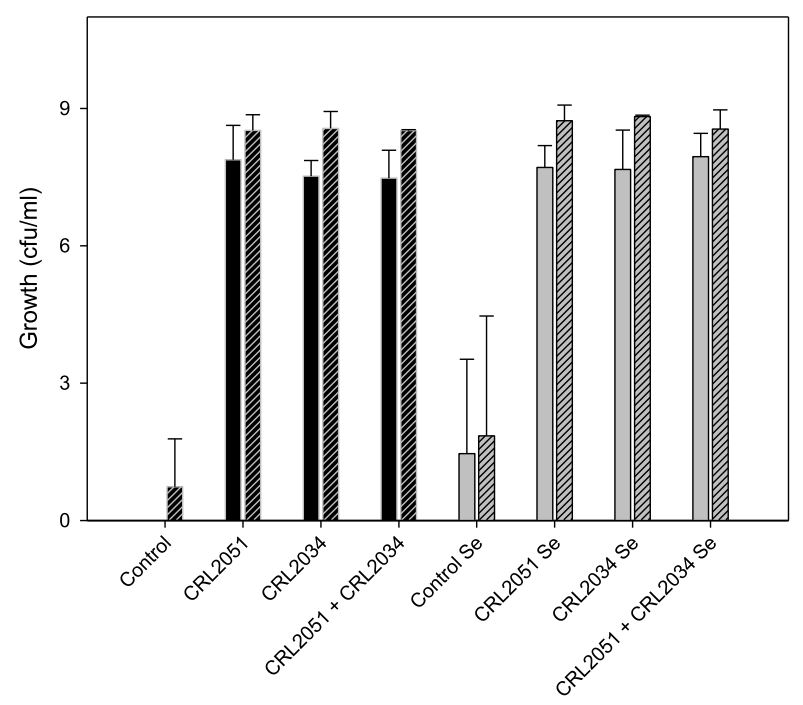

Pasteurised-MRS

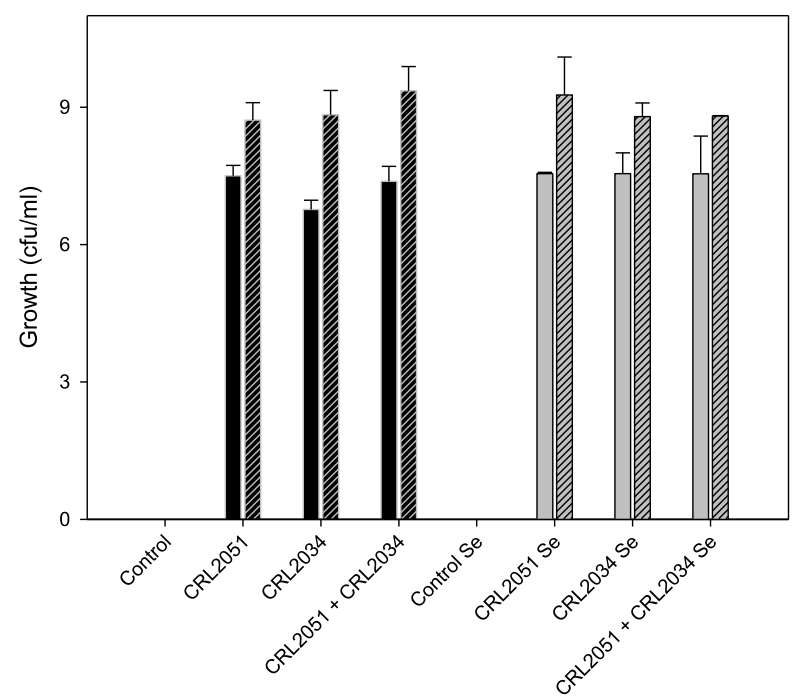

Raw-PCA

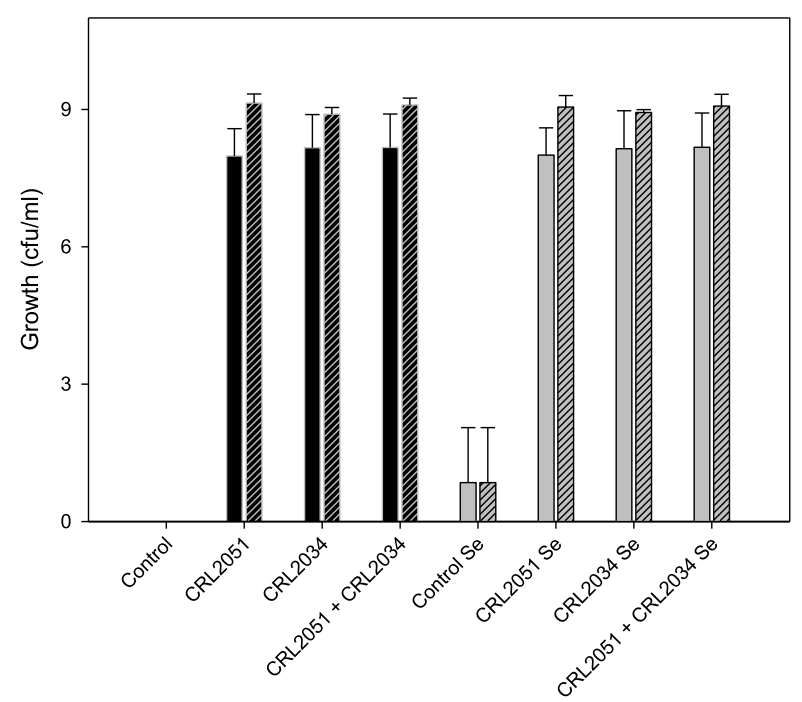

Pasteurised-PCA

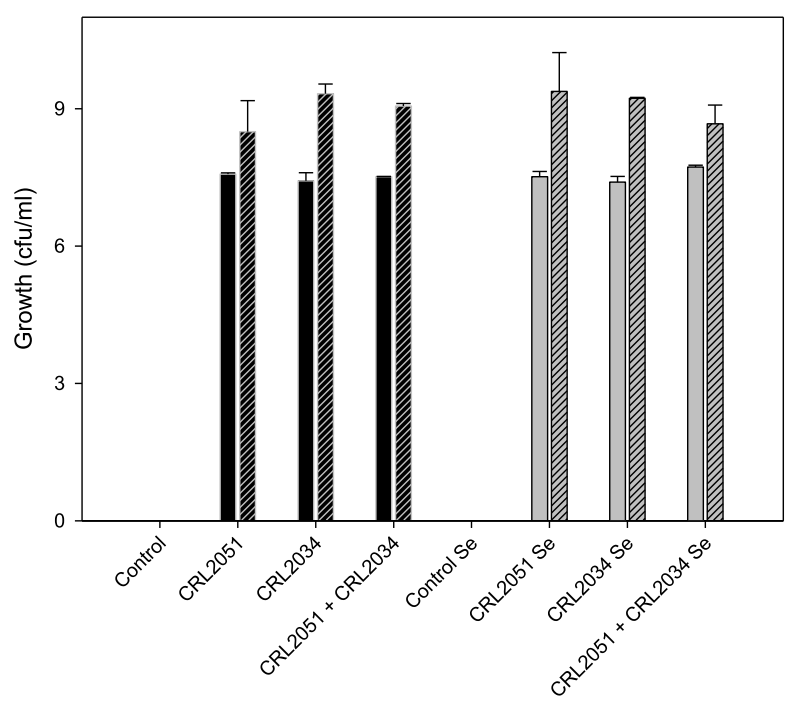

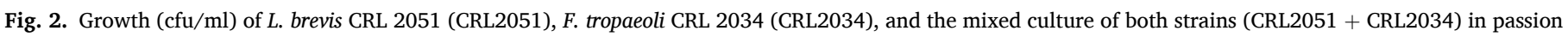

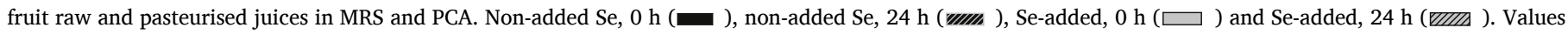
with different superscripts represent significant statistically data $(\mathrm{P}<0.05)$.

with F. tropaeoli CRL 2034 in the presence of Se (Figs. 1 and 3). Besides yeast and mold growth inhibition in mango/passion fruit juices, no significant differences in microbial cell counts between beverages with or without Se addition were observed. In addition, no significant differences in the growth of the strains alone or combined in mixed cultures were noticed (Figs 1-3). On the other hand, the applied pasteurization conditions of fruit juices were effective on preventing the growth of native microorganisms.

The initial $\mathrm{pH}$ values in mango juices were $5.5 \pm 0.3$, which decreased between 0.63 and 1.09 after $24 \mathrm{~h}$ incubation in raw inoculated and non-inoculated samples, while in pasteurised juices a $\mathrm{pH}$ decrease was observed only for the inoculated samples either using single or mixed cultures. On the other hand, as passion fruit juices had an initial $\mathrm{pH}$ of 2.5-3.0 the addition of sodium bicarbonate was necessary to increase the initial $\mathrm{pH}$ value up to 4.2 to allow bacterial growth. In the pasteurised and raw passion fruit samples, $\mathrm{pH}$ decrease was observed only for the inoculated juices ( 0.2 and 0.52 at $24 \mathrm{~h}$ ), and the lowest $\mathrm{pH}$ value was detected when the juice was fermented by $L$. brevis CRL 2051 (3.8 at 24 h). Consistently, in the mango/passion fruit juices, no acidification was observed in non-inoculated pasteurised and raw samples, while in the inoculated juices a $\mathrm{pH}$ decrease, between 0.21 and 0.64 was noticed. The highest acidification was observed in the pasteurised juice inoculated with the $L$. brevis strain. In general, no differences when Se was added to the juices were observed. 
Raw-MRS
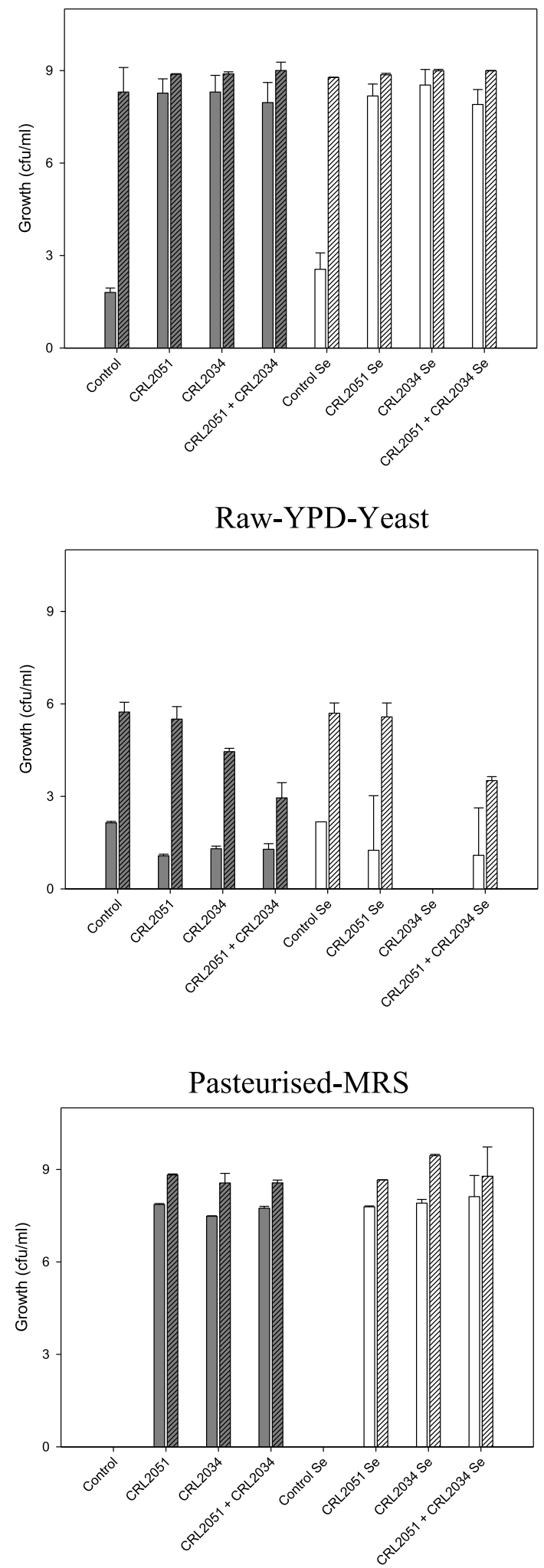
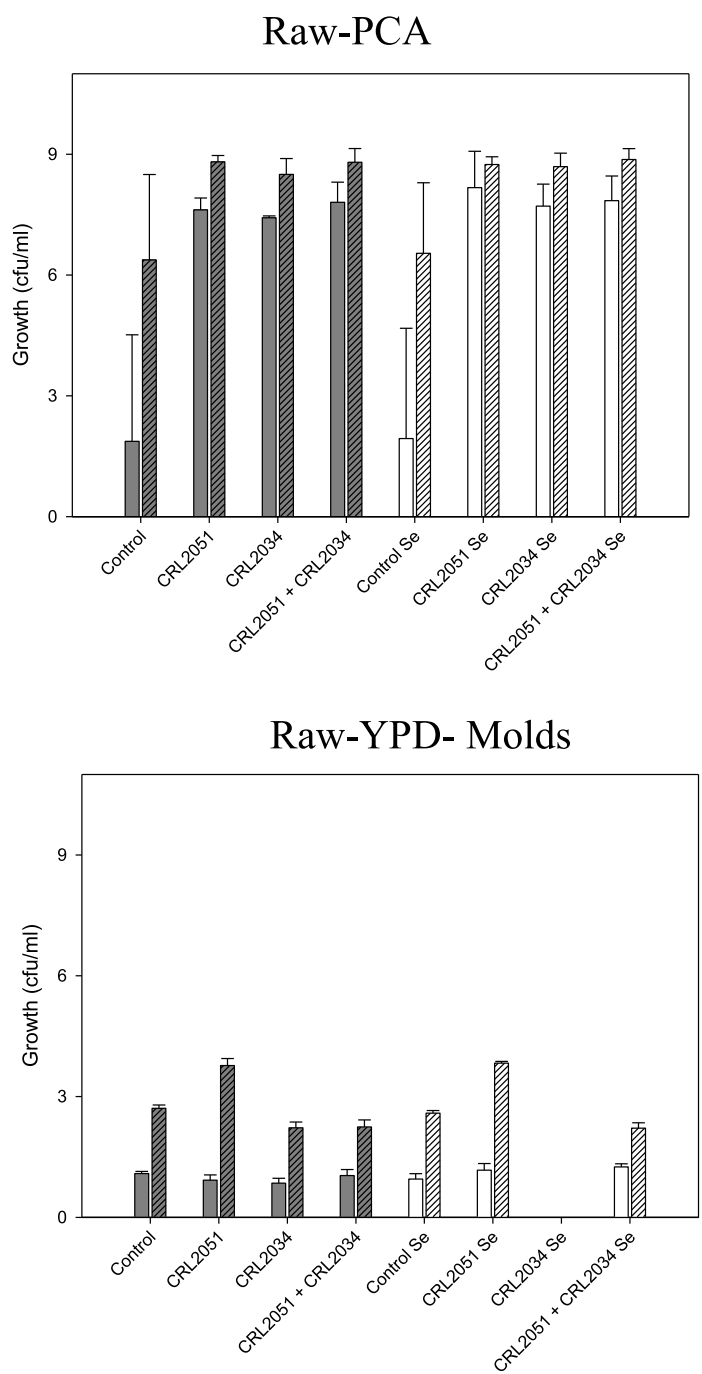

Pasteurised-PCA

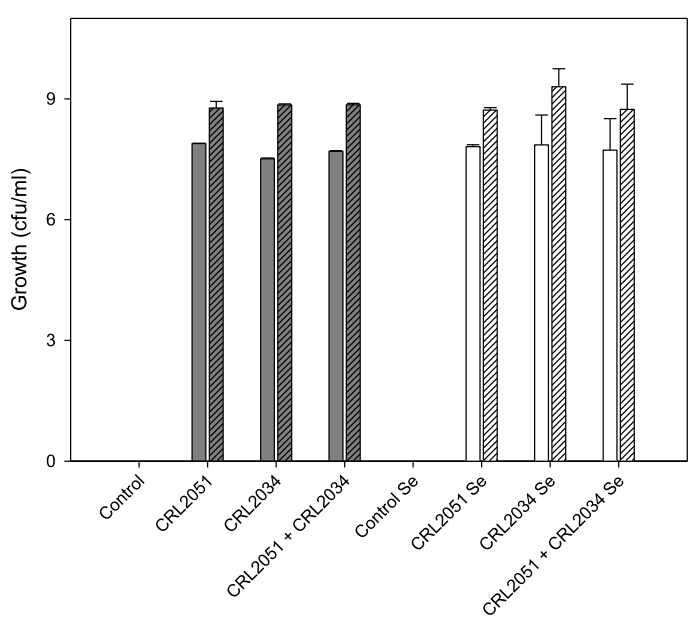

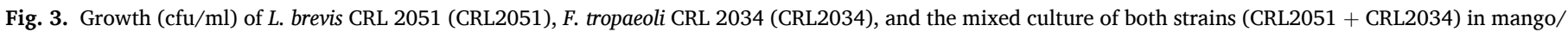

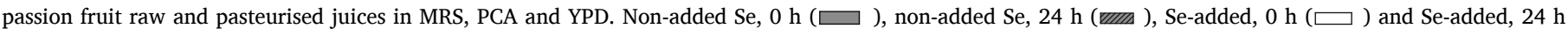
(שIIS ). Values with different superscripts represent significant statistically data $(\mathrm{P}<0.05)$. 


\subsection{Persistence of inoculated $L A B$ strains}

The studied LAB strains dominated the raw fruit juices fermentation; however, the autochthonous microorganisms were not completely displaced as revealed by the RAPD-PCR assays. Fig. 4 shows the differences of the bacterial diversity of mango/passion fruit non-pasteurised juices before and after fermentation. The inoculums formed two main clusters (A and B) showing a high frequency of isolation immediately after addition to the fruit juice (Fig. 4A). At the end of fermentation (Fig. 4B), the major group of isolates shared their polymorphic profiles with F. tropaeoli CRL 2034. Although the inoculums limited the development of the indigenous strains, some of them, especially those of clusters $C$ and D, were able to co-dominate the fermentation with the starter bacteria. Similar evolutions were registered also for the other fruit juices (data not shown). Thus, considering the safety of the formulated beverages, further analyses such as Se accumulation by LAB were conducted only for the pasteurised samples.

\subsection{Illumina data analysis of the microbiota in fermented tropical juice samples}

As combined culture-dependent and -independent approaches represent the best strategy to provide deepen information on the microbiota of fermented foods (Terzić-Vidojević et al., 2020), the non-pasteurised fermented mango/passion fruit juices alone or with the mixed starter culture that accumulated Se the most, were processed by MiSeq Illumina technology to better investigate the effect of fermentation and the presence of Se on the total bacterial community of the raw juices. The DNA extracted from the eight fermented tropical fruit juice samples was always successful in amplifying the bacterial V3-V4 16S rRNA gene region and 378,421 paired-end sequences were obtained. By performing the taxonomy classification, operational taxonomy units (OTUs) belonging to Cyanobacteria phyla were discarded by a taxa filter plug-in implemented in QIIME2, because Cyanobacteria phyla reads are probably coming from amplification and sequencing of chloroplasts, that originated from Cyanobacteria (Gray, 1989).

Fig. 5 reports the relative abundances (\%) of the OTUs identified at bacterial genus in non-pasteurised mango/passion fruit juices. Seven bacterial groups, including one species (Leuconostoc mesenteroides), three genera (Burkholderia, Lactobacillus, and Fructobacillus), two families (Enterobacteriaceae and Xanthomonadaceae), and one order (Rickettsiales) represented the bacterial community of these juices. Noninoculated (control) trials, both with and without Se, showed a very high relative abundance of OTUs belonging to Rickettiales at time 0 , which was consistently reduced after fermentation. The control trial without the addition of selenite was also characterized by the presence of Lactobacillus, which completely disappeared after fermentation, when Enterobacteriaceae, Leuc. mesenteroides, and Burkholderia at very low percentage were detected. Almost the same bacterial community evolution was registered for the raw juice added with selenite. Inoculated juices with and without Se displayed high OTUs percentages (63.67-65.37\%) corresponding to Lactobacillus, the old name for Levilactobacillus (Zheng et al. (2020). At the beginning of fermentation, in the same two trials Fructobacillus constituted barely $12.66-13.09 \%$ of the total community, and the presence of Rickettsiales was revealed. After $24 \mathrm{~h}$ of fermentation, Fructobacillus increased up to more than $40 \%$, while Lactobacillus and Rickettsiales percentages decreased.

\subsection{Carbohydrate metabolism in fermented tropical fruit juices}

Mango was composed of sucrose (83.5 g/L), glucose (12.7 g/L), and fructose $(43.3 \mathrm{~g} / \mathrm{L})$ as revealed by HPLC (Fig. 6A). In inoculated mango juices, a slight decrease in the sucrose content (11.5-20.7\%) was observed during incubation with the assayed single and mixed starter cultures while glucose and fructose were consumed in higher extent (37.9-87.0\% and 16.3-54.3\%, respectively); the highest values corresponding to the $F$. tropaeoli fermented beverages. Regarding organic acid formation, $L$. brevis CRL 2051 produced only lactic acid (16.3-24.3 g/L), the highest concentration corresponding to the mango fermented juice with Se. On the other hand, in the F. tropaeoli CRL 2034 and the mixed culture fermented mango juices, lactic acid (5.0-5.5 g/L), acetic acid (1.5-2.3 g/L), and mannitol (11.1-18.1 g/L) were detected. Higher concentrations of mannitol and acetic acid were observed in juices fermented with $F$. tropaeoli CRL 2034 alone respect to those with the mixed starter cultures; the highest mannitol value $(18.1 \mathrm{~g} / \mathrm{L})$ was observed in the mango juice fermented by F. tropaeoli CRL 2034 when Se was added. Carbohydrates present in passion fruit juices were the same as those in mango although lower concentrations were detected. The sugar concentrations were as follows: sucrose $(5.9 \mathrm{~g} / \mathrm{L})$, glucose $(4.5 \mathrm{~g} /$ $\mathrm{L}$ ), and fructose ( $4.3 \mathrm{~g} / \mathrm{L})$. The L. brevis strain consumed less glucose and fructose than F. tropaeoli CRL 2034 (1.1 and $1.8 \mathrm{~g} / \mathrm{L}$, respectively) and the mixed culture (1.4 and $1.8 \mathrm{~g} / \mathrm{L}$, respectively), and produced only lactic acid $(4.7 \mathrm{~g} / \mathrm{L})$. No differences in the sugar and acid concentrations after $24 \mathrm{~h}$ incubation were detected between juices with and without Se. In juices fermented by $F$. tropaeoli CRL 2034 and the mixed LAB culture the presence of lactic acid (2.2-4.0 and 1.7-2.6 g/L, respectively), acetic acid (0.8-1.5 and 0.6-1.0 g/L, respectively) and mannitol (3.2-4.0 and $2.7-4.1 \mathrm{~g} / \mathrm{L}$, respectively) was detected at $24 \mathrm{~h}$. Although no differences in organic acid and mannitol concentration were observed between the mixed culture and the $F$. tropaeoli fermented juices, a higher concentration of lactic acid (34.0-45.4\%), acetic acid (31.7-35.7\%), and mannitol (19.6-34.6\%) was noticed when Se was added in both fermented samples (Fig. 6B). Similarly, when the mixed mango/passion fruit was fermented, $F$. tropaeoli CRL 2034 consumed more glucose (5.7 $\mathrm{g} / \mathrm{L}$ ) and fructose (4.1 g/L) than L. brevis CRL 2051 (3.8 and $5.5 \mathrm{~g} / \mathrm{L}$ of glucose and 1.9 and $2.6 \mathrm{~g} / \mathrm{L}$ of fructose) without or with Se addition, respectively (Fig. 6C). Moreover, while L. brevis CRL 2051 produced only lactic acid (2.2 and $3.6 \mathrm{~g} / \mathrm{L}$, without and with Se addition, respectively) after $24 \mathrm{~h}$ incubation, in the $F$. tropaeoli and mixed culture fermented juices also acetic acid and mannitol were detected. F. tropaeoli CRL 2034 produced similar amounts of lactic (1.1 and $1.3 \mathrm{~g} / \mathrm{L})$ and acetic acid $(0.8-0.9 \mathrm{~g} / \mathrm{L})$ in both Se-containing and non-Se added samples, while a higher $(37.3 \%)$ mannitol amount was observed in the presence of Se.

\subsection{Selenium accumulation by $L A B$ in tropical fermented fruit juices}

Se concentration in the pellets was increased (at $24 \mathrm{~h}$ incubation) in all mango juices where Se was added (Fig. 7). Moreover, some Se was detected after $24 \mathrm{~h}$ incubation in samples without Se addition $(0.92 \mu \mathrm{g} /$ L). On the other hand, $14 \mu \mathrm{g} / \mathrm{L}$ of Se in the non-inoculated passion fruit juice with added selenite were detected after $24 \mathrm{~h}$ incubation; this concentration increased when the juice was fermented by L. brevis CRL 2051 (92.0 $\mu \mathrm{g} / \mathrm{L} ; 85.0 \%)$, F. tropaeoli CRL 2034 (86.0 $\mu \mathrm{g} / \mathrm{L} ; 83.9 \%)$, and the mixed starter culture $(123.0 \mu \mathrm{g} / \mathrm{L} ; 88.8 \%)$. In the non-inoculated mango/passion fruit juice (with Se) $15 \mu \mathrm{g} / \mathrm{L}$ of Se were found and the highest Se concentration $(70 \mu \mathrm{g} / \mathrm{L})$ was detected when the juice was fermented by the mixed culture, while the lowest amount $(51 \mu \mathrm{g} / \mathrm{L})$ was observed when using F. tropaeoli CRL 2034 alone.

\subsection{Total phenolic compounds content of fermented fruit juices}

In general, no differences in the total phenolic compound concentration between time $0(0.08$ and $0.136 \mathrm{GAE} / \mathrm{ml})$ and $24 \mathrm{~h}$ incubation ( 0.08 and $0.147 \mathrm{GAE} / \mathrm{ml}$ ) in mango juices without and with Se, respectively, were observed (Fig. 8). However, the phenolic compound values were higher in the presence of Se than in the samples without Se added. In the passion fruit juices no differences in the total phenolic compounds $(0.58 \pm 0.01 \mathrm{GAE} / \mathrm{ml}$ and $0.60 \pm 0.01 \mathrm{GAE} / \mathrm{ml}$, at time 0 and $24 \mathrm{~h}$, respectively) were observed between fermented samples at 0 and 24 h-incubation; moreover, no effect on Se addition was detected. On the other hand, a similar behavior to that observed in the mango juice was detected for the mango/passion fruit samples being the total 
A

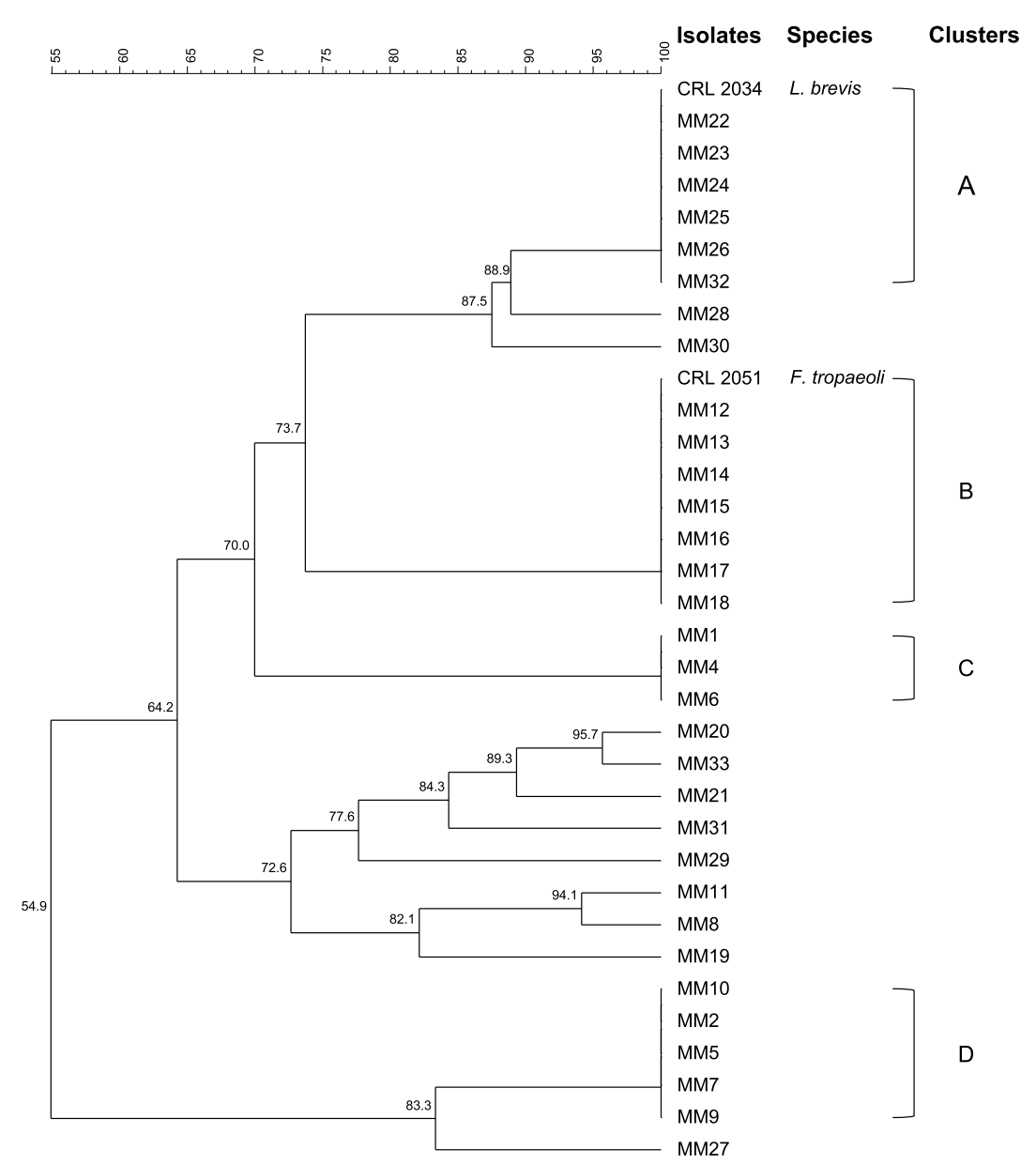

B

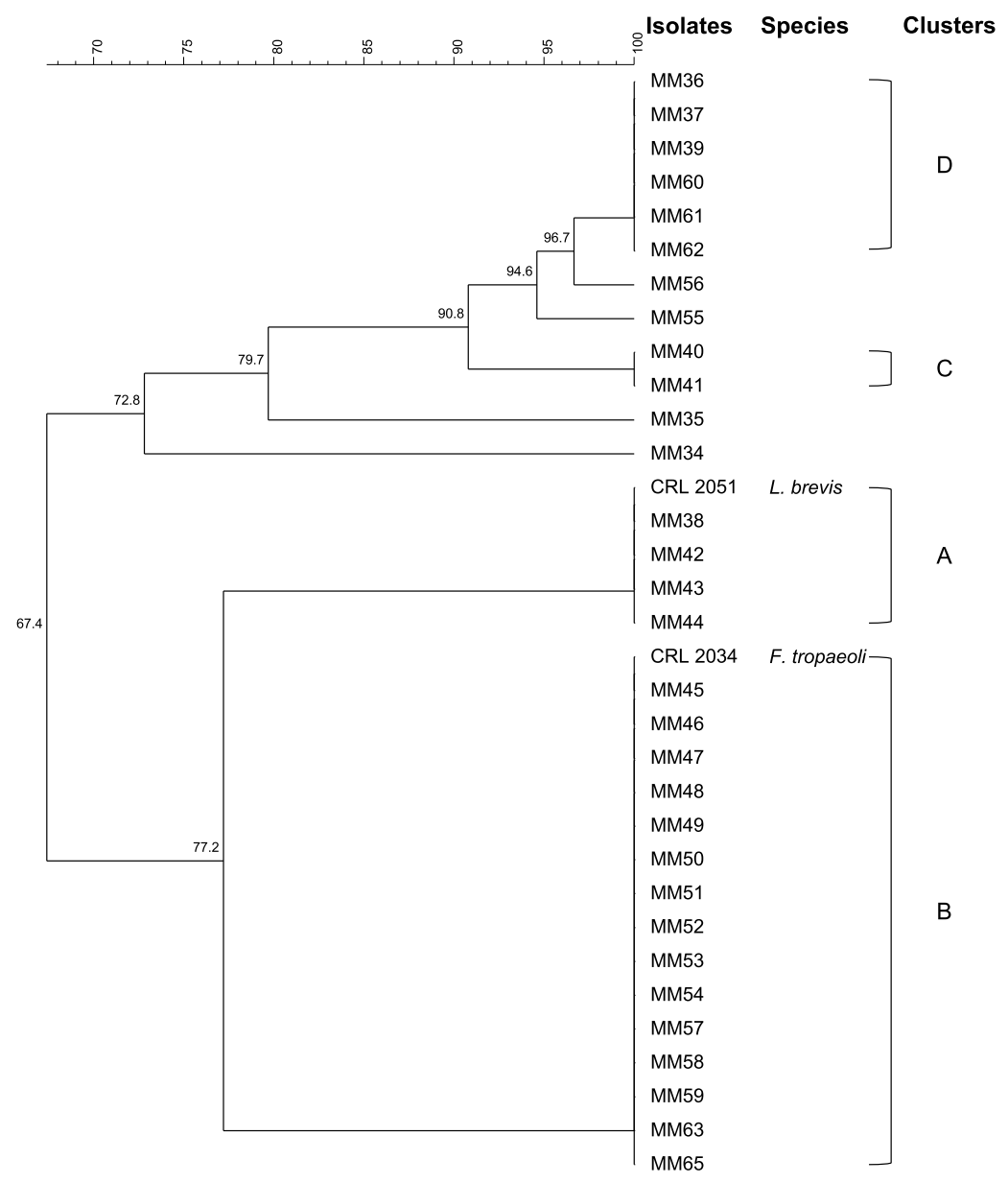

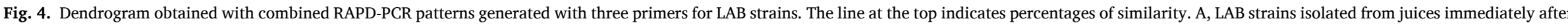
preparation $(0 \mathrm{~h})$; B, LAB strains isolated from juices after $24 \mathrm{~h}$ of fermentation. Abbreviations: L., Levilactobacillus; F., Fructobacillus. 


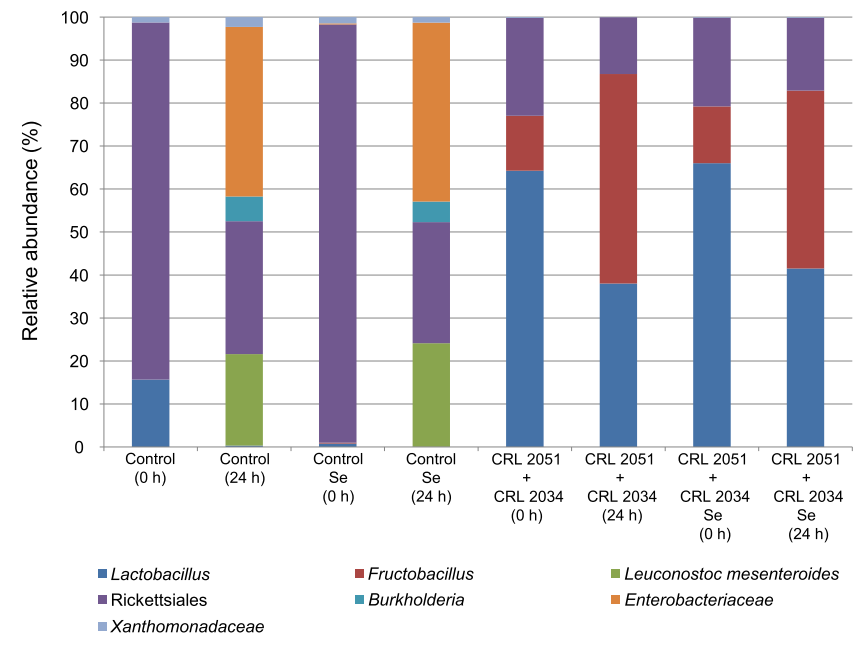

Fig. 5. Relative abundances (\%) of bacteria identified by MiSeq Illumina in raw mango/passion fruit juices. Trials: Control $(0 \mathrm{~h})$, non-inoculated raw juice immediately after preparation; Control (24 h), raw juice after $24 \mathrm{~h}$ of fermentation; Control Se $(0 \mathrm{~h})$, raw juice containing $\mathrm{Na}_{2} \mathrm{SeO}_{3}$ immediately after preparation; Control Se $(24 \mathrm{~h})$, raw juice containing $\mathrm{Na}_{2} \mathrm{SeO}_{3}$ after $24 \mathrm{~h}$ of fermentation; CRL 2051 + CRL 2034 (0 h), raw juice inoculated with L. brevis CRL 2051 and $F$. tropaeoli CRL 2034 immediately after production; CRL $2051+$ CRL 2034 (24 h), raw juice inoculated with L. brevis CRL 2051 and F. tropaeoli CRL 2034 after 24 h of fermentation; CRL 2051 + CRL 2034 Se (0 h), raw juice containing $\mathrm{Na}_{2} \mathrm{SeO}_{3}$ and inoculated with L. brevis CRL 2051 and F. tropaeoli CRL 2034 immediately after production; CRL 2051 + CRL 2034 Se (24 h), raw juice containing $\mathrm{Na}_{2} \mathrm{SeO}_{3}$ and inoculated with L. brevis CRL 2051 and F. tropaeoli CRL 2034 after $24 \mathrm{~h}$ of fermentation.

phenolic compound concentration higher ( $2.48 \pm 0.35$ times $)$ when Se was present. However, an increase in the phenolic compound concentration in the mango/passion fruit juices fermented by $F$. tropaeoli CRL 2034 ( $3.42 \pm 0.01$ fold $)$ and the mixed starter culture ( $1.26 \pm 0.07$ fold $)$ was observed after $24 \mathrm{~h}$ incubation.

\section{Discussion}

Fruits are highly susceptible to spoilage by deteriorating microorganisms and new technologies for increasing their storage period are needed (Patil \& Kamble, 2011; Ruiz Rodríguez et al., 2021. Fruit fermentation by LAB is a profitable technology, which may improve food safety and shelf-life (Di Cagno et al., 2013). Moreover, the consumption of fermented beverages has increased worldwide due to their health-promoting characteristics (Sloan, 2019). In particular, fermented fruit beverages are unique products in which the nutritive characteristics of fruits are combined with the health and safety properties of LAB. To date, several fruits have been proved to be suitable for fermentation by different starter cultures (Di Cagno et al., 2010; Di Cagno, Filannino, \& Gobbetti, 2017; Fessard et al., 2017; Isas et al., 2020; Veron, Di Risio, Isla, \& Torres, 2017). In this context, Se bioenrichment of fruit juices would provide an essential micronutrient to a novel, low caloric, dairy-free fermented food product. Fermented fruit beverages are in their early stage of development and further analysis of their nutritive and safety characteristics must be analyzed (Marsh, Hill, Ross, \& Cotter, 2014). Xinxing et al. (2019) reported that selenized cells of a Streptococcus thermophilus strain could grow and acidify a sterile orange, carrot, apple and Chinese jujube juice in a mixed culture with a Bifidobacterium breve and a $L$. plantarum strain; however, the final Se content of the fermented juice was not analyzed. In this work, we showed that two fruit origin $\mathrm{LAB}$ strains alone or combined were able to grow in three different raw tropical fruit juice preparations with and without Se addition. Although these LAB strains dominated the fermentation, they could not completely eliminate the autochthonous fruit microorganisms
A)

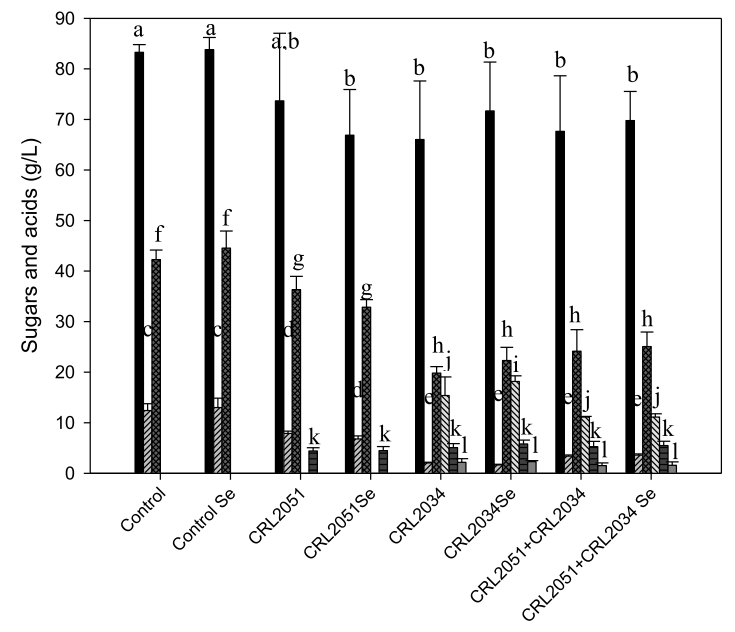

B)

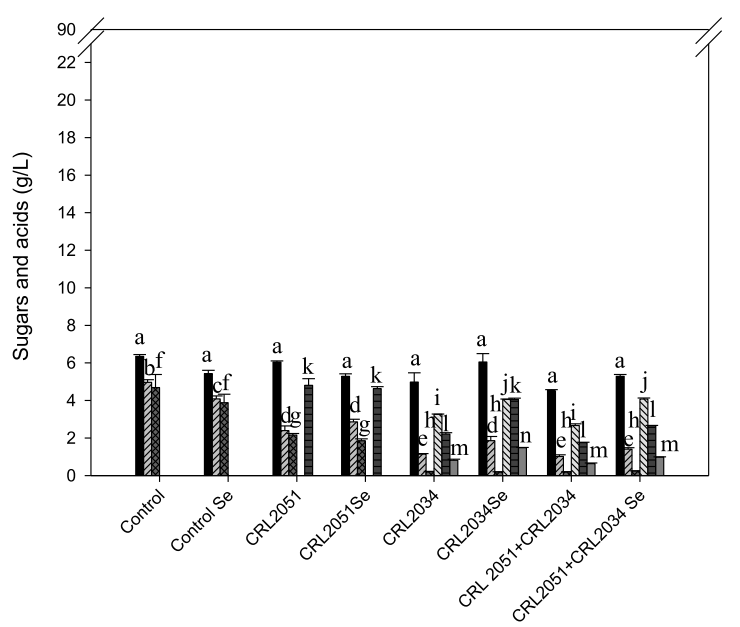

C)

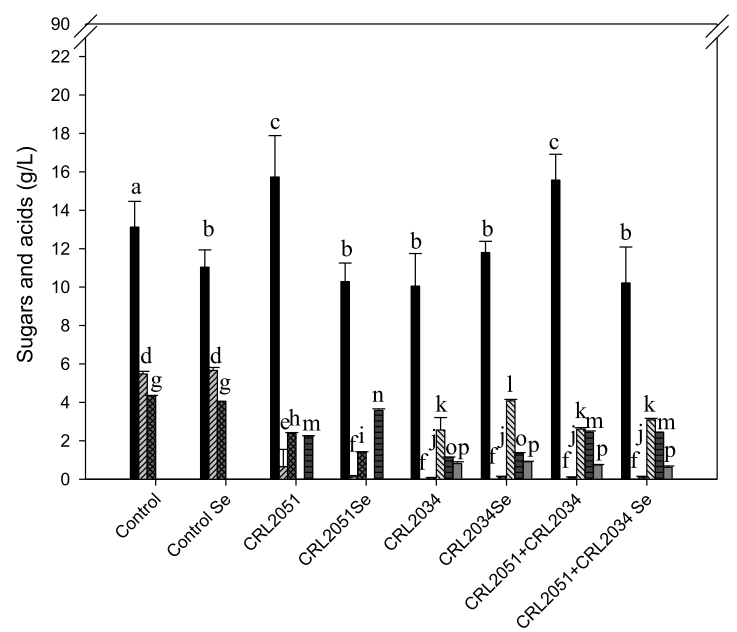

Fig. 6. Carbohydrate consumption (saccharose , glucose fructose ) and mannitol ( ) and organic acids (lactic acid and acetic acid $\square$ ) production by L. brevis CRL 2051(CRL2051), F. tropaeoli CRL 2034 (CRL2034), and the mixed culture of both strains (CRL2051 + CRL2034) in pasteurised non-added Se and Se added (Se) A) mango juice, B) passion fruit juice, and C) mango/passion fruit juice. Values with different superscripts represent significant statistically data $(\mathrm{P}<0.05)$ for each sugar or organic acid. 
A)

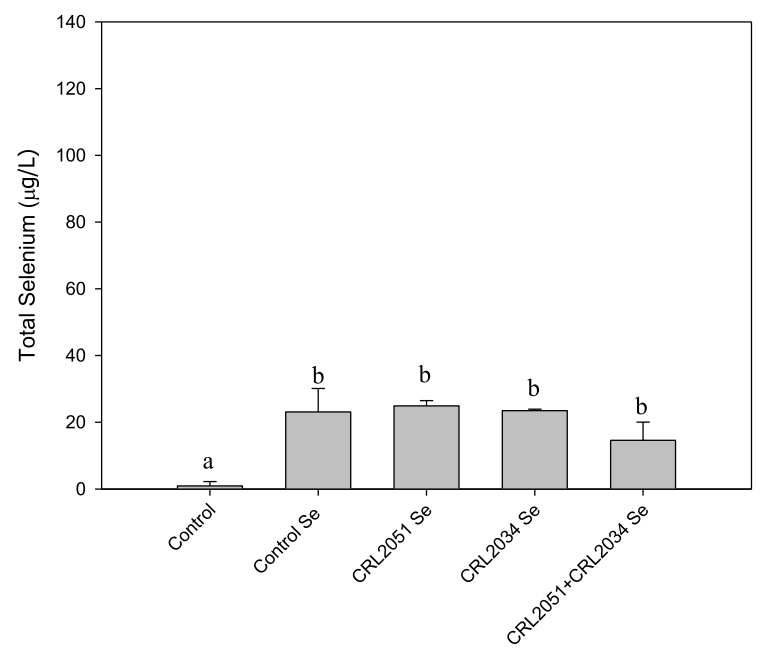

B)

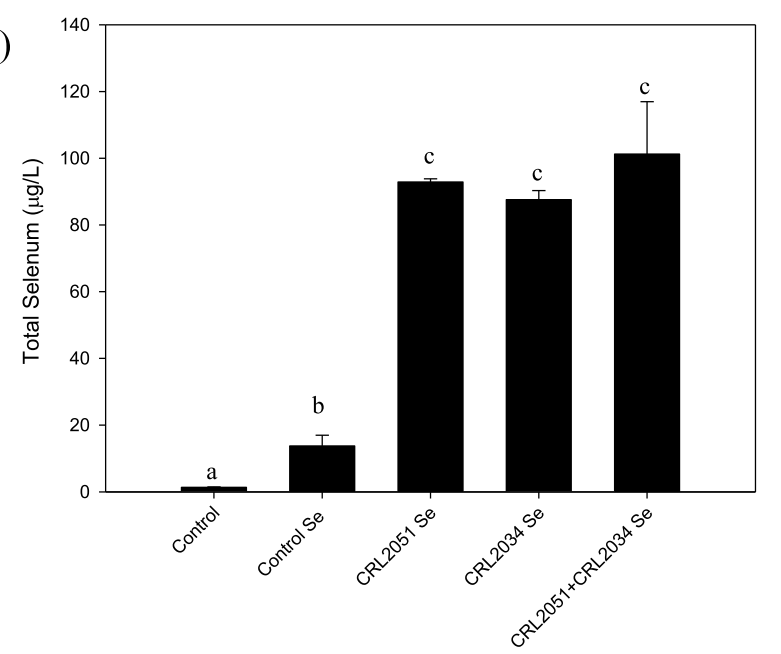

C

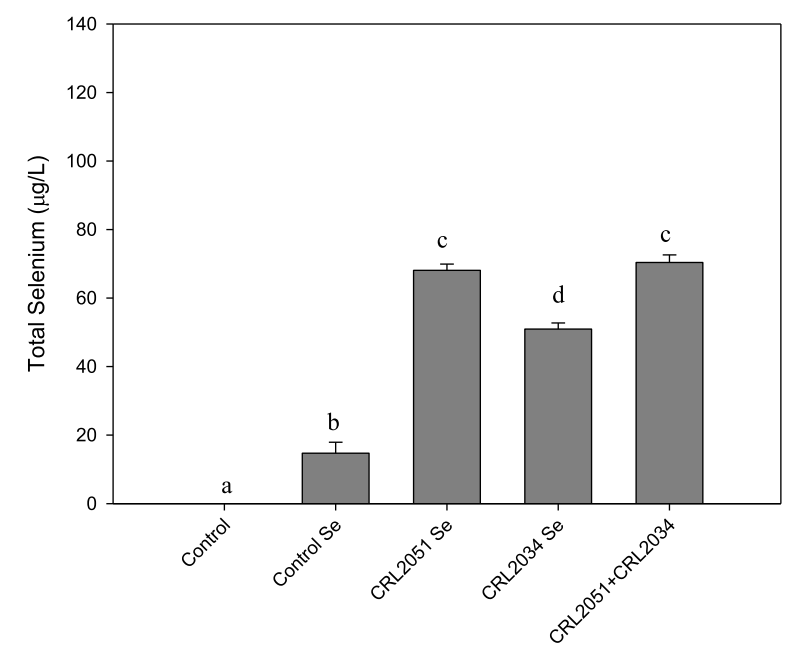

Fig. 7. Selenium accumulation in the pasteurised A) mango, B) passion fruit, and C) mango/passion fruit juices by L. brevis CRL 2051 (CRL2051), F. tropaeoli CRL 2034 (CRL2034) and the mixed culture of both strains (CRL2034 +CRL2051).
A)

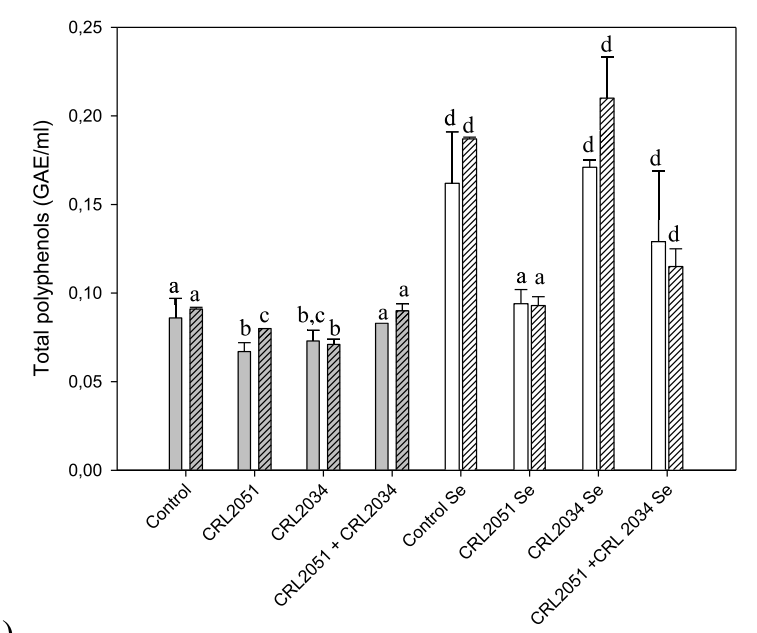

B)

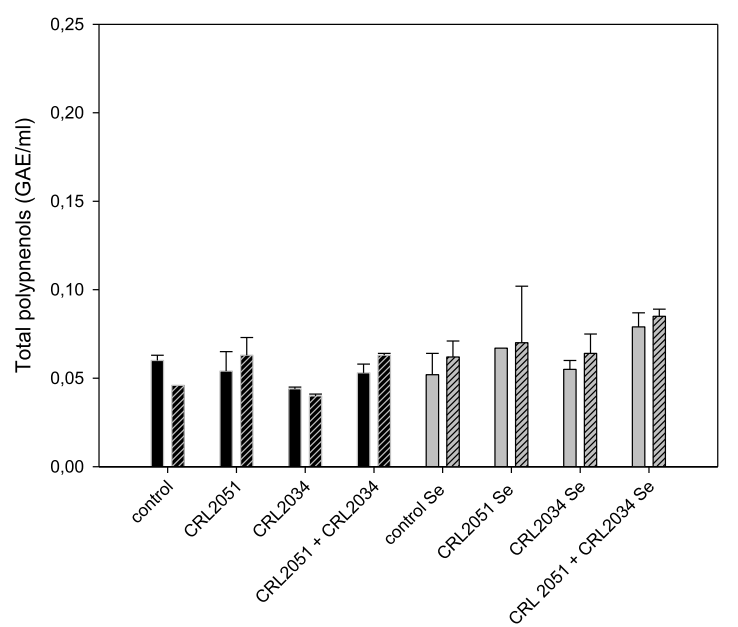

C)

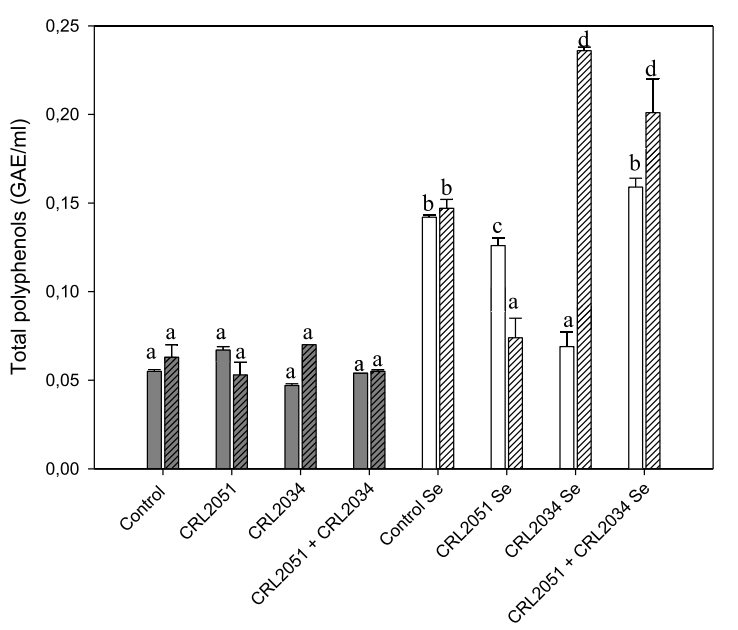

Fig. 8. Total polyphenol content $(\mathrm{GAE} / \mathrm{ml})$ of the fermented pasteurised bev-

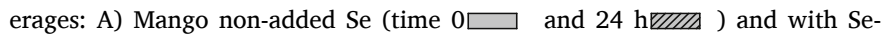
added (time $0 \square$ and $24 \mathrm{~h} \square \mathbf{m}$ ), B) passion fruit non-added Se (time

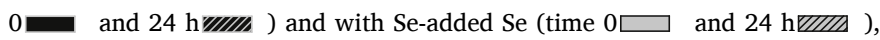
and C) mango/passion fruit non-added Se (time $0 \square$ and 24 h $\square$ (ID ) and with added Se (time $0 \square$ and $24 \mathrm{~h}$ ZII ) by L. brevis CRL 2051 (CRL2051), F. tropaeoli CRL 2034 (CRL2034) and the mixed culture of both strains (CRL2051 + CRL2034). Values with different superscripts represent significant statistically data $(\mathrm{P}<0.05)$. 
in unpasteurised juices as the presence of other bacteria was revealed by RAPD-PCR and metagenomics analyses. Metagenomics has the advantage of overcoming the limits of cultivation to detect the dominant bacterial microorganisms responsible for food fermentation (Bigot, Meile, Remize, \& Strub, 2015) as well as to evidence diverse microbial groups present in different raw fruit juices subjected to fermentation. In general, the variability of fermenting bacteria during the fermentation of vegetable and fruit juices is particularly high and strictly depends on the matrix (Choi et al., 2003; Di Cagno et al., 2009; Nicomrat \& Chamutpong, 2017). The presence of a high percentage of Rickettsiales in the studied raw tropical fruit juice before fermentation is imputable to environmental contamination, since members of this order are basically pathogens of vertebrate and invertebrate hosts (Yu \& Walker, 2006), and can be isolated from fruit flies associated to rotten fruits (Mohammed, Zuki, Yusof, \& Yaakop, 2015). In addition, Burkholderia genus includes several fruit contaminant species (Lou et al., 2011; Wang, Shi, \& Wang, 2018), while Lactobacillus is a member of the indigenous microbiota of fruit juices (Ruiz Rodriguez et al., 2019; Suárez-Jacobo, Gervilla, Guamis, Roig-Sagués, \& Saldo, 2010). On the other hand, by culture dependent methods, the presence of molds and yeasts were observed in mango and mango/passion fruit juices. These microorganisms are naturally present in fruits; however, no growth of these microorganisms was observed in the passion fruit non-pasteurised samples, probably due to the thickness of passion fruit peel and its very acidic $(\mathrm{pH}$ 2.5) environment.

The carbohydrate metabolism by the studied strains in the fruit juices was analyzed in pasteurised samples. L. brevis strains are commonly present in plant materials and can simultaneously consume glucose with other fermentable sugars due to their relaxed hierarchical control of carbohydrate utilization (Kim, Shoemaker, \& Mills, 2009). Indeed, consumption of both fructose and glucose by this LAB species is observed, although glucose is not drained. Moreover, L. brevis CRL 2051 produced only lactic acid, despite the fact that is a heterofermentative species; it has already been stated that when strains of $L$. brevis are grown in mixed sugar cultures containing glucose, acetate and ethanol are not produced, probably due to the lower requirements for cofactor (NAD/NADP) regeneration (Martínez et al., 2019). On the other hand, when F. tropaeoli CRL 2034 or the mixed culture of this strain with L. brevis were used for juice fermentation, the presence of mannitol, lactic acid, and acetic acid were detected. Fructobacilli are common inhabitants of fruits and flowers rich in fructose and thus, are able to use glucose only in the presence of an external electron acceptor such as fructose, pyruvate or oxygen (Endo, 2012). Moreover, the absence of an alcohol dehydrogenase obliges them to regenerate $\mathrm{NAD}^{+}$through mannitol production by the enzymatic activity of a mannitol dehydrogenase enzyme (Ruiz Rodríguez, Bleckwedel, Eugenia Ortiz, Pescuma, \& Mozzi, 2017). In this work, fermented fruit juices with added Se showed a higher production of mannitol by the Fructobacillus strain. It has been reported that a zinc-containing alcohol dehydrogenase was involved in selenite reduction in a strain of Stenotrophomonas maltophilia (Lampis et al., 2016). Mannitol production is an interesting feature during food fermentation since it reduces the high amounts of metabolizable sugars present in some fruits into a low-caloric sweetener (Ortiz et al., 2012).

Se concentration of fermented fruit juices was determined in the microbial cell pellets, since inorganic selenite is soluble, the Se present in precipitates correspond to insoluble Se nanoparticles (SeNPs) and/or intracellularly accumulated Se as seleno-amino acids by the bacteria used as starter culture. In this work, LAB were able to accumulate Se in the fruit pellet of the passion fruit and the mixed passion fruit/mango juices. The Se present in the pellet of the non-fermented mango juice could be due to the high-water holding capacity of the fruit pulp, in which selenite could be trapped in the fruit matrix. Indeed, we observed that mango pulp behaved as a pseudoplastic fluid. Manohar, Ramakrishna, and Ramteke (1990) reported that the high pectin content of mango pulp was responsible for its high viscosity $(48 \%)$. In passion fruit and mixed mango/passion fruit juices, the Se accumulation values were in a range of $34-67 \%$ of the added Se in the inoculated samples. Due to the low concentration of Se added to the juices (corresponding to half of the recommended dietary allowance), the detection of the Se species in the pellets was not possible since a previous fractionation by chromatographic procedures is necessary and a minimum Se concentration is mandatory for a correct peak resolution. However, in a previous work, we determined that L. brevis CRL 2051 and F. tropaeoli CRL 2034 bio-transformed selenite into selenocysteine (SeCys) and SeNP (Martínez et al., 2020). SeCys is an essential amino acid present in selenoproteins with antioxidant, antiaging, and anticancerogenic properties such as thioredoxin reductase, glutathion peroxidase, iodothyronine deiodinases, etc. (Gómez-Gómez, Pérez-Corona, Mozzi, Pescuma, \& Madrid, 2019).

Finally, fruits are rich in phenolic compounds which are known to have antioxidant and anticarcinogenic activities (Coban et al., 2012; Ruiz Rodríguez et al., 2021). However, these compounds are often present as complex molecules bound with sugars or proteins. LAB are able to degrade polyphenols into simpler components by decarboxylation, reduction, de-esterification, and deglycosylation reactions (Lee \& Paik, 2017). The release of simple phenolic compounds can be measured as an increase in the concentration of total phenols in the fermented fruit supernatants. F. tropaeoli CRL 2034 could increase the concentration of free phenolic compounds in mango and mango/passion fruit juices when Se was added.

The production of novel functional fermented foods using fruits is an interesting alternative for including beneficial microbes to non-dairy foods suitable for vegans and lactose-intolerant individuals as well as obese, diabetic, and cholesterol-related patients.

\section{Conclusions}

This work showed that $F$. tropaeoli CRL 2034 or the mixed starter culture with L. brevis CRL 2051 could be used for formulating a mango/ passion fruit functional beverage bio-enriched in Se with lower sugar content and increased free phenolic compound concentration.

\section{Credit author statement}

Laura Crespo (microbiology studies), Fernando G. Martinez (ICPMS), Raimondo Gaglio (microbiology studies and RAPD-PCR), Micaela Pescuma (microbiology studies), Elena Franciosi (16S Illumina library and sequencing) and Gustavo Moreno Martin (ICP-MS) conducted the experimental work and analyzed the results and contributed on the manuscript writing. Fernanda Mozzi, Luca Settanni, Yolanda Madrid Albarrán and Micaela Pescuma directed and designed the work, and wrote and revised the manuscript. All authors read and approved the submitted version.

\section{Declaration of competing interest}

The authors declare not to have conflict of interest.

\section{Acknowledgements}

Authors thank the financial support of the bilateral cooperation project between University of Palermo (Italy) and CERELA-CONICET (Argentina) program CONICET-CUIA 2017 (\# 24120170100014CO), and projects PICT-2014-0312 and PICT-2015-2330 of FONCyT and PIP2014-003 from CONICET, Argentina.

\section{References}

Alfonzo, A., Gaglio, R., Miceli, A., Francesca, N., Di Gerlando, R., Moschetti, G., et al. (2018). Shelf-life evaluation of fresh-cut red chicory subjected to different minimal processes. Food Microbiology, 73, 298-304.

Alfonzo, A., Urso, V., Corona, O., Francesca, N., Amato, G., Settanni, L., et al. (2016). Development of a method for the direct fermentation of semolina by selected 
sourdough lactic acid bacteria. International Journal of Food Microbiology, 239, 65-78.

Baker, G. C., Smith, J. J., \& Cowan, D. A. (2003). Review and re-analysis of domainspecific 16S primers. Journal of Microbiological Methods, 55, 541-555.

Bates, R. P., Morris, J. R., \& Crandall, P. G. (2001). Principles and practices of small-and medium-scale fruit juice processing. Agricultural Services Bulletin No. 146. Rome: FAO.

Bigot, C., Meile, J. C., Remize, F., \& Strub, C. (2015). Applications of metagenomics to fermented foods. Fermented Foods, Part I (Biochemistry Biotechnol), 333-346.

Bokulich, N. A., Kaehler, B. D., Rideout, J. R., Dillon, M., Bolyen, E., Knight, R., et al. (2018). Optimizing taxonomic classification of marker-gene amplicon sequences with QIIME 2's q2-feature-classifier plugin. Microbiome, 6, 90.

Callahan, B. J., Mc Murdie, P. J., Rosen, M. J., Han, A. W., Johnson, A. J. A., \& Holmes, S. P. (2016). DADA2: High-resolution sample inference from Illumina amplicon data. Nature Methods, 13, 581-583.

Choi, I. K., Jung, S. H., Kim, B. J., Park, S. Y., Kim, J., \& Han, H. U. (2003). Novel Leuconostoc citreum starter culture system for the fermentation of kimchi, a fermented cabbage product. Antonie van Leeuwenhoek, 84, 247-253.

Coban, D., Milenkovic, D., Chanet, A., Khallou-Laschet, J., Sabbe, L., Palagani, A., et al (2012). Dietary curcumin inhibits atherosclerosis by affecting the expression of genes involved in leukocyte adhesion and transendothelial migration. Molecular Nutrition \& Food Research, 56, 1270-1281.

Cruciata, M., Gaglio, R., Scatassa, M. L., Sala, G., Cardamone, C., Palmeri, M., et al. (2018). Formation and characterization of early bacterial biofilms on different wood typologies applied in dairy production. Applied and Environmental Microbiology, 84, 02107-02117.

Di Cagno, R., Cardinali, G., Minervini, G., Antonielli, L., Rizzello, C. G., Ricciuti, P., et al. (2010). Taxonomic structure of the yeasts and lactic acid bacteria microbiota of pineapple (Ananas comosus L. Merr.) and use of autochthonous starters for minimally processing. Food Microbiology, 27(3), 381-389.

Di Cagno, R., Coda, R., De Angelis, M., \& Gobbetti, M. (2013). Exploitation of vegetables and fruits through lactic acid fermentation. Food Microbiology, 33, 1-10.

Di Cagno, R., Filannino, P., \& Gobbetti, M. (2017). Lactic acid fermentation drives the optimal volatile flavor-aroma profile of pomegranate juice. International Journal of Food Microbiology, 248, 56-62.

Di Cagno, R., Surico, R. F., Paradiso, A., De Angelis, M., Salmon, J. C., Buchin, S., et al. (2009). Effect of autochthonous lactic acid bacteria starters on health-promoting and sensory properties of tomato juices. International Journal of Food Microbiology, 128, 473-483.

Endo, A. (2012). Fructophilic lactic acid bacteria inhabit fructose-rich niches in nature. Microbial Ecology in Health and Disease, 23, 18563.

Garcia, C., Guérin, M., Souidi, K., \& Remize, F. (2020). Lactic fermented fruit or vegetable juices: Past, present and future. Beverages, 6, 8.

Gómez-Gómez, B., Pérez-Corona, T., Mozzi, F., Pescuma, M., \& Madrid, Y. (2019). Silacbased quantitative proteomic analysis of Lactobacillus reuteri CRL 1101 response to the presence of selenite and selenium nanoparticles. Journal of Proteomics, 195, 53-65.

Granato, D., Branco, G. F., Cruz, A. G., Faria, J. A. F., \& Nazzaro, F.( (2010). Functional foods and nondairy probiotic food development: Trends, concepts and products. Comprehensive Reviews in Food Science and Food Safety, 9, 292-302.

Gray, M. W. (1989). The evolutionary origins of organelles. Trends in Genetics, 5, 294-299.

Isas, A. S., Mariotti Celis, M. S., Pérez Correa, J. R., Fuentes, E., Rodríguez, L., Palomo, I., et al. (2020). Functional fermented cherimoya (Annona cherimola Mill.) juice using autochthonous lactic acid bacteria. Food Research International, 138, 109729.

Joy, P. P. (2014). Passion fruit production. Technology (Adhoc). Vazhakulam-686 670, Muvattupuzha, Ernakulam District, Kerala, India: Pineapple Research Station (Kerala Agricultural University).

Kim, J. H., Shoemaker, S. P., \& Mills, D. A. (2009). Relaxed control of sugar utilization in Lactobacillus brevis. Microbiology, 155, 1351-1359.

Lampis, S., Zonaro, E., Bertolini, C., Cecconi, D., Monti, F., Micaroni, M., et al. (2016). Selenite biotransformation and detoxification by Stenotrophomonas maltophilia SeITE02: Novel clues on the route to bacterial biogenesis of selenium nanoparticles. Microbial Biotechnology, 9, 758-771.

Lee, N. K., \& Paik, H. D. (2017). Bioconversion using lactic acid bacteria: Ginsenosides, GABA, and phenolic compounds. Journal of Microbiology and Biotechnology, 27. https://doi.org/10.4014/jmb.1612.12005

Lou, M. M., Zhu, B., Muhammad, I., Li, B., Xie, G. L., Wang, Y. L., et al. (2011). Antibacterial activity and mechanism of action of chitosan solutions against apricot fruit rot pathogen Burkholderia seminalis. Carbohydrate Research, 346, 1294-1301.

Manohar, B., Ramakrishna, P., \& Ramteke, R. S. (1990). Effect of pectin content on flow properties of mango pulp concentrates. Journal of Texture Studies, 21, 179-190.

Marsh, A. J., Hill, C., Ross, P. R., \& Cotter, P. D. (2014). Fermented beverages with health-promoting potential: Past and future perspectives. Trends in Food Science \& Technology, 38, 113-124.
Martínez, F. G., Cuencas Barrientos, M. E., Mozzi, F., \& Pescuma, M. (2019). Survival of selenium-enriched lactic acid bacteria in a fermented drink under storage and simulated gastro-intestinal digestion. Food Research International, 123, 115-124.

Martínez, F. G., Martin-Moreno, G., Pescuma, M., Madrid-Albarrán, Y., \& Mozzi, F. (2020). Biotransformation of selenium by lactic acid bacteria: Formation of selenonanoparticles and seleno-amino acids. Frontiers in Bioengineering and Biotechnology. https://doi.org/10.3389/fbioe.2020.00506

Mohammed, M. A., Zuki, A. A., Yusof, S., \& Yaakop, S. (2015). Isolation and characterization of Wolbachia (Rickettsiales: Rickettsiaceace) from several economic importance parasitoids (Hymenoptera: Braconidae). International Journal of Bioscience, Biochemistry and Bioinformatics, 5(4), 256.

Nicomrat, D., \& Chamutpong, S. (2017). Diversified microbial community developed in different fruit juice of wine fermentation. Applied Mechanics and Materials, 866, 57-60.

Ortiz, M. E., Fornaguera, M. J., Raya, R. R., \& Mozzi, F. (2012). Lactobacillus reuteri CRL 1101 highly produces mannitol from sugarcane molasses as carbon source. Applied Microbiology and Biotechnology, 95, 991-999.

Patil, S., \& Kamble, V. (2011). Antibacterial activity of some essential oils against foodborne pathogen and food spoilage bacteria. International Journal of Pharma Bio Sciences, 2, 143-150.

Pescuma, M., Gómez Gómez, B., Perez Corona, T., Madrid, Y., \& Mozzi, F. (2017). Food prospects of selenium enriched-Lactobacillus acidophilus CRL 636 and Lactobacillus reuteri CRL 1101. Journal of Functional Foods, 35, 466-473.

Ruiz Rodríguez, L., Bleckwedel, J., Eugenia Ortiz, M., Pescuma, M., \& Mozzi, F. (2017). Lactic acid bacteria. In C. Wittmann, \& J. C. Liao (Eds.), Industrial biotechnology: Microorganisms (pp. 395-451).

Ruiz Rodriguez, L. G., Mohamed, F., Bleckwedel, J., Medina, R., De Vuyst, L., Hebert, E. M., et al. (2019). Diversity and functional properties of lactic acid bacteria isolated from wild fruits and flowers present in Northern Argentina. Frontiers in Microbiology, 10, 1091.

Ruiz Rodríguez, L. G., Zamora Gasga, V. M., Pescuma, M., Van Nieuwenhove, C., Mozzi, F., \& Sanchez Burgos, J. A. (2021). Fruits and fruit by-products as sources of bioactive compounds. Benefits and trends of lactic acid fermentation in the development of novel fruit-based functional beverages. Food Research International, 140, 109854.

Septembre-Malaterre, A., Stanislas, G., Douraguia, E., \& Gonthier, M.-P. (2016). Evaluation of nutritional and antioxidant properties of the tropical fruits banana, litchi, mango, papaya, passion fruit and pineapple cultivated in Réunion French Island. Food Chemistry, 212, 225-233.

Siezen, R. J., \& Bachmann, H. (2008). Genomics of dairy fermentations. Microbial Biotechnology, 1(6), 435-442.

Singleton, V. L., Orthofer, R., \& Lamuela-Raventos, R. M. (1999). Analysis of total phenols and other oxidation substrates and antioxidants by means of Folin-Ciocalteu reagent. Methods in Enzymology, 299, 152-178.

Suárez-Jacobo, Á., Gervilla, R., Guamis, B., Roig-Sagués, A. X., \& Saldo, J. (2010). Effect of UHPH on indigenous microbiota of apple juice: A preliminary study of microbial shelf-life. International Journal of Food Microbiology, 136, 261-267.

Swain, M. R., Anandharaj, M., Ray, R. C., \& Parveen Rani, R. (2014). Fermented fruits and vegetables of Asia: A potential source of probiotics. Biotechnology Research International. https://doi.org/10.1155/2014/250424

Szutowska, J. (2020). Functional properties of lactic acid bacteria in fermented fruit and vegetable juices: A systematic literature review. European Food Research and Technology, 1-16.

Terzić-Vidojević, A., Veljović, K., Tolinački, M., Živković, M., Lukić, J., Lozo, J., et al. (2020). Diversity of non-starter lactic acid bacteria in autochthonous dairy products from Western Balkan Countries-technological and probiotic properties. Food Research International, 136, 109494.

Vithana, M. D. K., Singh, Z., \& Johnson, S. K. (2019). Regulation of the levels of health promoting compounds: Lupeol, mangiferin and phenolic acids in the pulp and peel of mango fruit: A review. Journal of the Science of Food and Agriculture, 99, 3740-3751.

Wang, X., Shi, J., \& Wang, R. (2018). Effect of Burkholderia contaminans on postharvest diseases and induced resistance of strawberry fruits. Plant Pathology Journal, 34, 403.

Xinxing, X., Yejun, B., Bingbing, W., Fei, L., Xiaosong, H., \& Jihong, W. (2019). Chemical analysis and flavor properties of blended orange, carrot, apple and Chinese jujube juice fermented by selenium-enriched probiotics. Food Chemistry, 289, 250-258.

Yu, X. J., \& Walker, D. H. (2006). The order Rickettsiales. Prokaryotes, 5, 493-528.

Zheng, J., Wittouck, S., Salvetti, E., Franz, C. M. A. P., Harris, H. M. B., Mattarelli, P., et al. (2020). A taxonomic note on the genus Lactobacillus: Description of 23 novel genera, emended description of the genus Lactobacillus Beijerinck 1901, and union of Lactobacillaceae and Leuconostocaceae. International Journal of Systematic and Evolutionary Microbiology, 70, 2782-2858. 